\title{
Current and novel polymeric biomaterials for neural tissue engineering
}

\author{
Rossana Boni ${ }^{1}$, Azam Ali ${ }^{1 *}$, Amin Shavandi ${ }^{1,3}$ and Andrew N. Clarkson ${ }^{2}$
}

\begin{abstract}
The nervous system is a crucial component of the body and damages to this system, either by of injury or disease, can result in serious or potentially lethal consequences. Restoring the damaged nervous system is a great challenge due to the complex physiology system and limited regenerative capacity.

Polymers, either synthetic or natural in origin, have been extensively evaluated as a solution for restoring functions in damaged neural tissues. Polymers offer a wide range of versatility, in particular regarding shape and mechanical characteristics, and their biocompatibility is unmatched by other biomaterials, such as metals and ceramics. Several studies have shown that polymers can be shaped into suitable support structures, including nerve conduits, scaffolds, and electrospun matrices, capable of improving the regeneration of damaged neural tissues. In general, natural polymers offer the advantage of better biocompatibility and bioactivity, while synthetic or non-natural polymers have better mechanical properties and structural stability. Often, combinations of the two allow for the development of polymeric conduits able to mimic the native physiological environment of healthy neural tissues and, consequently, regulate cell behaviour and support the regeneration of injured nervous tissues.

Currently, most of neural tissue engineering applications are in pre-clinical study, in particular for use in the central nervous system, however collagen polymer conduits aimed at regeneration of peripheral nerves have already been successfully tested in clinical trials.

This review highlights different types of natural and synthetic polymers used in neural tissue engineering and their advantages and disadvantages for neural regeneration.
\end{abstract}

Keywords: Biomaterials, Synthetic and natural polymers, Neural tissue engineering, Axonal regeneration, Neuronal differentiation

\section{Introduction}

Tissue engineering combines principles and techniques of cell biology, material science, and engineering to fabricate tissue substitutes that mimic the structural and physiological nature of native tissue with the fundamental aim to regenerate the functional properties of an injured or diseased tissue [1].The regeneration and repair of both the central nervous system (CNS) and peripheral nervous system (PNS) remain crucial challenges in tissue engineering. The underlying reason is that both CNS and PNS have limited capacity for self-regeneration in mammals,

\footnotetext{
* Correspondence: azam.ali@otago.ac.nz

${ }^{1}$ Bioengineering Research Team, Centre for Bioengineering and

Nanomedicine, Department of Food Science, University of Otago, PO Box 56,

Dunedin 9054, New Zealand

Full list of author information is available at the end of the article
}

and lasting functional deficits are common after disease and injury [2].

Impairments to the CNS can occur in a number of ways, such as trauma due to falls, car accidents, and assaults, which are the leading causes of long-term disability in both urban and rural population worldwide [3]. In addition, sport-related traumatic brain injuries contribute significantly in developed countries when compared to developing countries [3]. Neurodegenerative diseases, such as Alzheimer's Disease, Parkinson's Disease, Huntington Disease, prion disease, amyotrophic lateral sclerosis, and frontotemporal dementia, are a serious health problem resulting in discrete cell loss in specific brain regions [4]. Neurodegenerative diseases are insidious and progressive disorders and their incidence is on the rise as we have an aging population [5]. Stroke is also a leading

(c) The Author(s). 2018 Open Access This article is distributed under the terms of the Creative Commons Attribution 4.0 International License (http://creativecommons.org/licenses/by/4.0/), which permits unrestricted use, distribution, and 
cause of adult disability because of the brain's limited capacity for repair [6-8], with most surviving the stroke, but living with a lasting impairment [9]. Finally, brain tumours are amongst the leading causes of death and are the second most common cancer found in children [10].

In the CNS, reactive astrocytes and the formation of an inhibitory glia scar largely prevent regeneration of the damaged tissues [11]. Most of the current research has been focused towards preventing further damage and on the stabilisation of the affected area, with limited research directed towards understanding reparative processes to enhance recovery of lost functions associated with injury to the CNS.

In addition, the PNS is also vulnerable to different kinds of traumatic injuries due to the extensive presence of nerves throughout the body [12]. The most common types of traumatic peripheral nerve injuries are penetrating injury, crush injury, traction injury, ischemia, laceration, compression, and thermal injury [13-15]. Trauma due to motor vehicle accidents, penetrating trauma related to violence, falls, and occupational accidents are the most common causes of traumatic injuries to the PNS [16]. Nerve injuries have devastating consequences on a patient's quality of life, due to sensory and motor function defects which could be severe enough to paralyze the affected limb, combined with the development of excruciating neuropathic pain [17].

Currently, end-to-end neurorrhaphy is considered the clinical gold standard for the treatment of nerve gaps smaller than $1 \mathrm{~cm}$ and autologous nerve grafting is the common treatment for nerve damage exceeding $1 \mathrm{~cm}$ [18]. However, limited availability of nerve grafts, donor site morbidity, possible neuroma formation, and immunological responses are some of the critical issues limiting autologous nerve grafting as a therapeutic approach [12].

With the limitation of current therapeutic approaches for CNS and PNS injuries to be translated into the clinic, significant work has been directed towards developing novel neural tissue engineering strategies as potential treatments for tissue regeneration. Polymers, both synthetic and natural in origin, have shown consistent positive results in neural tissue engineering, including neurite outgrowth, differentiation of human neural stem cells, and nerve gap bridging [19-24]. New strategies aimed at the treatment of CNS and PNS injuries include polymeric scaffolds [25-29], hydrogels [23, 30-33], nanoparticles [34-37], and nerve conduits [20, 38-41]. The purpose of this review is to present an overview of the literature concerning polymeric applications, focusing particularly on the most recent discoveries, for neural tissue engineering and functional regeneration of nerve tissue.

\section{Neural tissue engineering}

During the last two decades, enormous progress has been made regarding our understanding of biological mechanisms regulating both CNS and PNS. Polymers have been largely used in neural tissue engineering due to their range of versatility that is unmatched by other biomaterials like metals and ceramics. The physical, chemical, mechanical, and inherent biological properties vary depending on the different polymer and each of these properties can be variated depending on the application they are being used for, such as 3D cell culture for PC12 cells, drug delivery vehicles, hydrogels, nerve conduits, and scaffolds. Successful polymeric structures not only offer mechanical support for growing neurites and inhibition of scar tissue, but they also regulate biological cues to guide axonal growth, promote regeneration, and stimulate integration into the existing healthy tissue [42, 43], Fig 1. Polymer nanoparticles are considered an optimal and versatile drug delivery system for regions like the brain. Polymer nanoparticles are able to protect therapeutic agents, cross the blood-brain barrier (BBB), and efficiently deliver drugs into damaged areas [44, 45], Fig. 2. Polymeric neural probes and electrodes have been successfully used as long-term chronically implantable neuroprosthetic devices for the treatment of neurodegenerative diseases, dystonia, chronic pain, and deep brain stimulation, becoming an invaluable clinical and diagnostic tool $[46,47]$.

\section{Natural polymers for neural tissue engineering}

In neural tissue engineering, the use of natural polymers is highly beneficial due to their high biocompatibility and natural biodegradation kinetics combined with chemically tuneable properties. Often, natural polymers are analogues, if not identical like in the case of collagen, to substances already present in the human body, minimising the risks of cytotoxicity and immunogenic reaction upon implantation in the body [43]. In neural tissue engineering, natural polymers can fulfil different roles, including matrix formers, gelling agents, or drug release modifiers, and they can be easily adjusted to fit a defect in a difficult physiological geometry, such as the spinal cord $[48,49]$. Natural polymers applied in neural tissue engineering have different origins, such as extracellular matrix components (ECM), like collagen, polymers derived from marine life, like alginate, polymers derived from crustaceans, like chitosan, and polymers derived from insects, like silk. Natural polymers are the most researched type of polymer in neural tissue engineering and they have been preclinically studied at length in numerous animal models, including primates. In addition, collagen is the only biopolymer currently approved for clinical studies aimed at peripheral nerve regeneration. However, weak mechanical characteristics 


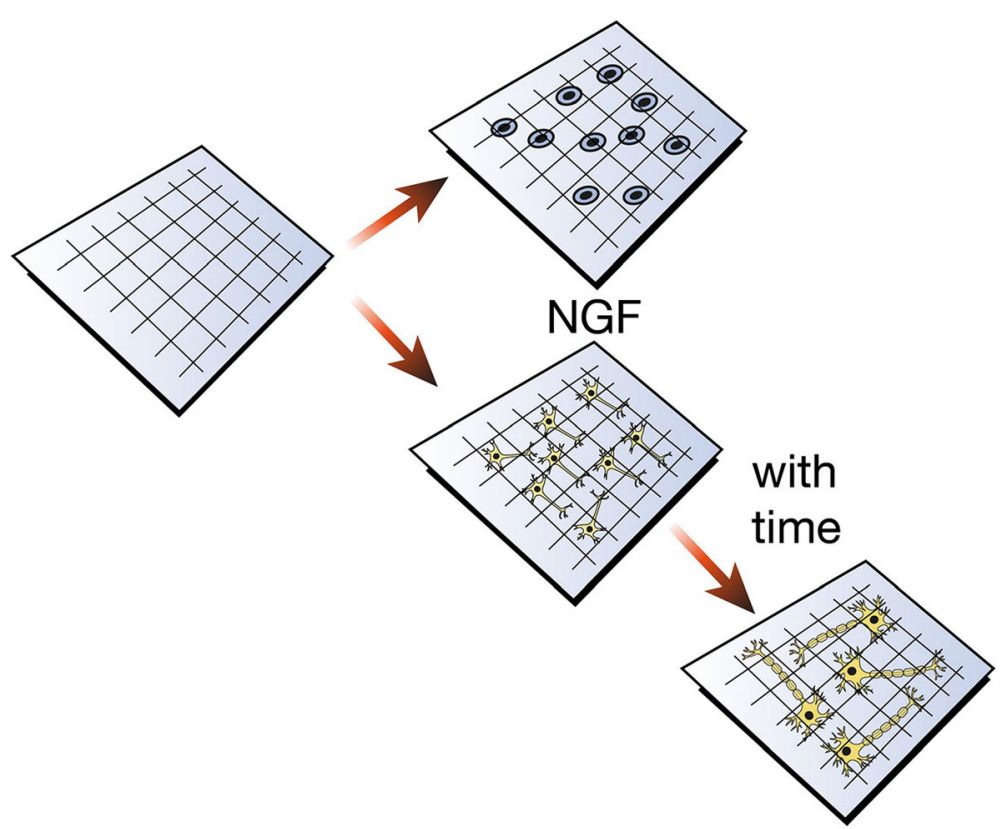

Fig. 1 Polymeric structure for neural regeneration. Polymeric structures seeded with NGF offer mechanical support for growing neurites that in time will differentiate into fully matured neurons. They regulate biological cues to guide axonal growth and sprouting, to promote the regeneration of the nerve tissue

due to complex chemical structures, thermal sensitivity, and processing difficulties that frequently require use of solvents, hinder the efficacy of natural polymers, prompting researchers to combine them with synthetic or electroconductive polymers. Table 1 summarises the main natural polymers used in neural tissue engineering and their applications.

\section{Collagen}

Collagen is a key structural biopolymer that makes up $30 \%$ of the mass of vertebrates, building their constitutional framework [50]. Humans have 28 proteins known as collagen and the most common is type I, a fibrillary type of collagen, the main component of connective tissues, which provide structure and support throughout the body, including bones, skin, tendons, cartilage, and nerves [50].

Collagen is a well-known biomaterial in neural tissue engineering. Early applications include the repair of a small $(5 \mathrm{~mm})$ nerve gap in non-human primates through a collagen based nerve guide that proved to be physiologically similar to a graft repair $[51,52]$. More recently, collagen conduits have been explored as a possible internal filler for neural conduits, increasing the quality of

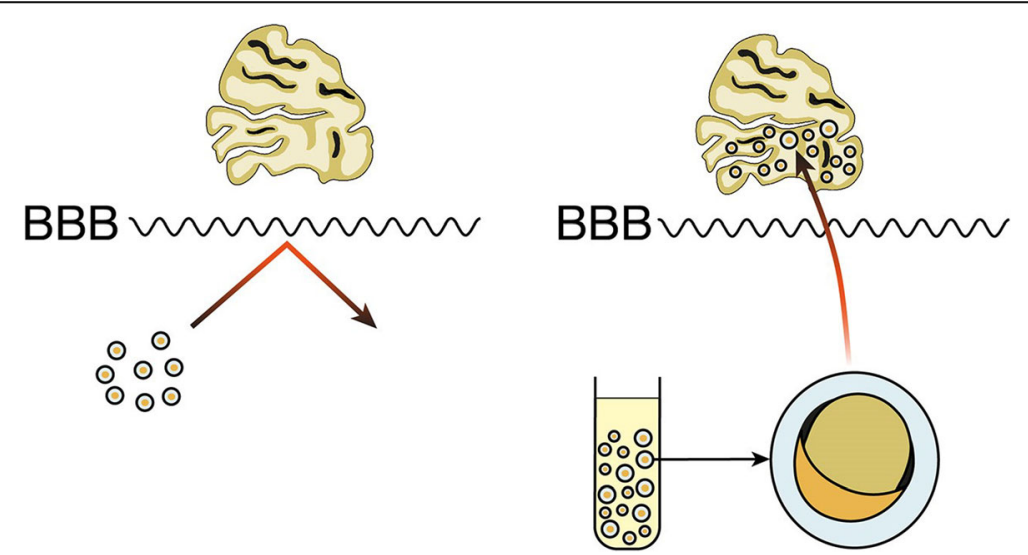

Fig. 2 Polymer coating allows crossing of the BBB. Uncoated therapeutic drugs are unable to cross the BBB, but polymer nanoparticles are able to protect specific therapeutic agents, cross the BBB, and efficiently deliver drugs into damaged areas 
Table 1 The main natural polymers used in neural tissue engineering, biocompatibility in vitro/in vivo, and examples of their applications

\begin{tabular}{|c|c|c|c|c|}
\hline Natural Polymer & Biocompatibility in vitro & Biocompatibility in vivo & Application & References \\
\hline \multicolumn{5}{|c|}{ Pre-clinical Studies } \\
\hline \multirow[t]{7}{*}{ Collagen } & & Non-human primates & Nerve guide & {$[51,52]$} \\
\hline & & Rats & Hydrogel/scaffold & {$[23,28]$} \\
\hline & & Dogs & Nerve conduits & [53] \\
\hline & & Cats & Nerve conduits & [54] \\
\hline & & Mice & Entubulation & [57] \\
\hline & DRGs & & Entubulation & [58] \\
\hline & & Rats & Entubulation & [59] \\
\hline Fish Collagen & rBMSCs & & $\begin{array}{l}\text { No influence on neural } \\
\text { differentiation }\end{array}$ & [63] \\
\hline \multirow[t]{10}{*}{ Gelatin } & hC-MSCs & & Electrospun conduits & [66] \\
\hline & PC12 & & Electrospun conduits & [67] \\
\hline & C17.2 & & Nerve conduits for Schwann cells & [68] \\
\hline & RT4-D6P2T & & Nerve conduits for Schwann cells & [168] \\
\hline & PC12 & & Nerve conduits for Schwann cells & [177] \\
\hline & & Rats & Nerve conduit & {$[178,181,182]$} \\
\hline & Allogeneic rMSCs & & Scaffold & [27] \\
\hline & Primary RSCs & Rats & Nanoparticles & [75] \\
\hline & PC12 & & Hybrid Scaffold & [184] \\
\hline & PC12 & & Bioink & {$[77,78]$} \\
\hline \multirow[t]{3}{*}{ Elastin } & & Mice & Thermally Responsive ELPs & [193] \\
\hline & PC12 & & ELPs Drug Depot & [194] \\
\hline & & Rats & ELPs Intranasal Drug Delivery & [195] \\
\hline \multirow{11}{*}{$\begin{array}{l}\text { Hyaluronic } \\
\text { Acid }\end{array}$} & & Rats & Hydrogel & [197] \\
\hline & $\begin{array}{l}\text { NPCs from forebrain cortical } \\
\text { neuroepithelium of E13.5 rats }\end{array}$ & & Hydrogel & [198] \\
\hline & C17.2 cells, ReNcells, GRPs & & Hydrogel & [199] \\
\hline & DRGs & & Hydrogel & [39] \\
\hline & NPCs & & Hydrogel & {$[28,202,203]$} \\
\hline & & Rabbits & Nerve Conduit & {$[189,206]$} \\
\hline & & Rats & Nerve Conduit & [48] \\
\hline & RSC96 & & Nerve Conduit & [192] \\
\hline & NSCs & & Drug Delivery & {$[93,94]$} \\
\hline & PC12 & & Nanoparticles & [207] \\
\hline & $\begin{array}{l}\text { Cerebral cortices of } \\
\text { Sprague-Dawley rats }\end{array}$ & & Coating & [208] \\
\hline \multirow[t]{7}{*}{ Alginate } & & Cats & Gel & {$[209,212,213]$} \\
\hline & & Rats & Gel & [210] \\
\hline & & Rats & Sponge & {$[211,215,216]$} \\
\hline & PDLMSCs and GMSCs & & Hybrid scaffold & [217] \\
\hline & PC12 & & Hybrid scaffold & [95] \\
\hline & NSCs & & Hybrid scaffold & [218] \\
\hline & & Rats & Hybrid scaffold & [108-111] \\
\hline
\end{tabular}


Table 1 The main natural polymers used in neural tissue engineering, biocompatibility in vitro/in vivo, and examples of their applications (Continued)

\begin{tabular}{|c|c|c|c|c|}
\hline Natural Polymer & Biocompatibility in vitro & Biocompatibility in vivo & Application & References \\
\hline \multirow[t]{12}{*}{ Chitosan } & PC12 & & Hydrogel & {$[26,76,120]$} \\
\hline & $\begin{array}{l}\text { NPCs from forebrain cortical } \\
\text { neuroepithelium of C } 57 \text { fetal rats }\end{array}$ & & Hydrogel & [113] \\
\hline & NSCs & & Hydrogel & {$[114,115]$} \\
\hline & Neuro-2a & & Scaffold & [116] \\
\hline & $\begin{array}{l}\text { Schwann cells from } \\
\text { Sprague-Dawley rats }\end{array}$ & & Scaffold & {$[117,118,123-125]$.} \\
\hline & U373 & & Nanotubes & [119] \\
\hline & BMSCs & & Scaffold & [121] \\
\hline & & Dogs & Scaffold & [122] \\
\hline & GFP+RG3.6 & & Micro/nano vehicle & [126] \\
\hline & & Rats & Micro/nano vehicle & {$[34,127]$} \\
\hline & & Mice & Micro/nano vehicle & [128] \\
\hline & hNSC & & Bioink & [129] \\
\hline \multirow[t]{5}{*}{ Keratin } & & Mice & Nerve guide & {$[131,132,134]$} \\
\hline & RT4-D6P2T & Mice & Hydrogel & [133] \\
\hline & & Rabbits & Hydrogel & [135] \\
\hline & & Primates & Hydrogel & [136] \\
\hline & Glial cells & & Nanofibrous Scaffold & [137] \\
\hline \multirow[t]{12}{*}{ Silk } & NSCs & & Hydrogel & {$[30,141]$} \\
\hline & & Rats & Hydrogel & [39] \\
\hline & DRGs & & Hydrogel & $\begin{array}{l}{[139,140,143,145,} \\
147]\end{array}$ \\
\hline & $\begin{array}{l}\text { Primary Hippocampal } \\
\text { Neurons }\end{array}$ & & Scaffold & [144] \\
\hline & PC12 & & Electrospun scaffold & [146] \\
\hline & & Rats & Electrospun scaffold & {$[39,40]$} \\
\hline & & Dogs & Electrospun scaffold & [24] \\
\hline & & Rats & Nerve Guide & [148] \\
\hline & & Rats & Electrode Coating & [149] \\
\hline & Glial Scarring & & Electrode Coating & [150] \\
\hline & NT2 & & Nerve guide (spider silk) & [151] \\
\hline & NSCs & & Matrix (spider silk) & [152] \\
\hline \multicolumn{5}{|l|}{ Clinical Studies } \\
\hline \multirow[t]{2}{*}{ Collagen } & & $\begin{array}{l}\text { Peripheral nerve } \\
\text { reconstruction }\end{array}$ & NeuraGen ${ }^{\oplus}$ & {$[55]$} \\
\hline & & $\begin{array}{l}\text { Peripheral nerve } \\
\text { reconstruction }\end{array}$ & Neuromaix ${ }^{\circledast}$ & [56] \\
\hline
\end{tabular}

DRGs: dorsal root ganglia; rBMSCs: rat bone marrow mesenchymal stem cells; $h C-M S C s$ : human chorion mesenchymal stem cells; $r M S C s$ : rat mesenchymal stromal cells; RSCs: rat Schwann cells; ELPs: elastin-like polypeptides; NPCs: neural progenitor cells; GRPs: human glial-restricted precursors; PDLMSCs: human periodontal ligament mesenchymal stem cells; GMSCs: gingiva-derived mesenchymal stem cells; NSCs: neural stem cells; BMSCs: bone marrow stromal cells; hNSCs: human neural stem cells.

peripheral nerve regeneration over longer gaps. Collagen hydrogels improved the regeneration of a $15 \mathrm{~mm}$ gap in rat sciatic nerve [23] and collagen conduits combined with NGF partially reconstructed a $35 \mathrm{~mm}$ sciatic nerve defect in a dog model [53].Collagen is also used in combinations with other biopolymers and proteins. For instance, the electrophysiological evaluation of a collagen-PGA tube confirmed its role as a promising biomaterial for nerve conduits for peripheral nerve regeneration in cats [54] while a linear ordered collagen 
scaffold crosslinked with laminin, a key protein of the ECM in the nervous system, guided axonal growth and enhanced nerve regeneration as well as functional recovery in rats [28].

Collagen has been extensively studied as a biomaterial for neural tissue engineering and as a result, numerous collagen based nerve guides are commercially available on the market for peripheral nerves regeneration. Currently, collagen is the only biopolymer approved for clinical testing in neural tissue engineering. For example, NeuraGen ${ }^{\circ}$ proved to be highly effective in peripheral nerve reconstruction in $43 \%$ of patients [55]. Another promising commercially available collagen nerve guide, Neuromaix $^{\circ}$, showed outstanding results in bridging long nerve gaps in its first clinical trial [56]. It is clear that collagen based nerve conduits are the most biocompatible nerve conduit currently available in clinical settings, and its efficacy is often comparable to the clinical gold standard, autologous nerve grafting.

An interesting application of collagen is entubulation, hence the use of magnetically aligned type I collagen gel, achieved by exposing the forming collagen gel to a high-strength magnetic field, as a filler for collagen tubes. This method was successful in small peripheral nerve lesions, improving significantly nerve regeneration in a $6 \mathrm{~mm}$ nerve gap in mice [57] and guiding neurite elongation and Schwann cell invasion in vitro [58] and in vivo [59].

Fish collagen has attracted interest as an alternative to its bovine counterpart. Fish collagen can be obtained from the by-products of fish and invertebrate processing, in form of skin, bone, and scales [60]. Fish collagen has been investigated as a potential biomaterial due to its advantageous biological characteristics, such as excellent biocompatibility, low antigenicity, high level of cell adhesion, and excellent biodegradability [61]. Fish collagen scaffolds, 2D or 3D, exhibit considerable cell viability, comparable to that of bovine collagen and they have been used for both soft and hard tissue applications [61, 62]. However, there is little to no work done on fish collagen for neural tissue engineering and, despite its promising features as a biomaterial, research carried out by Liu et al. stated that hydrolysed fish collagen promotes osteogenic and endothelial differentiation from bone marrow stem cells, but it does not function as a neural-inducing factor [63]. For the moment, the findings of Liu et al. combined with the relative lack of information regarding the use of fish collagen in neural tissue engineering limit its application in this field.

\section{Gelatin}

Gelatin is a denatured protein obtained by hydrolysis of animal collagen with either acid or alkaline. Gelatin has a long history of safe use in pharmaceuticals, cosmetics, and food products due to its broad array of advantages, including low cost, availability, high biocompatibility, and biodegradability. Further, as a denatured product, gelatin is less antigenic than collagen and its chemically modifiable structure allows modulation of cell adhesion and proliferation, improving the biological behaviour of a polymeric device upon implantation [64].

Primarily, gelatin has found applications in neural tissue engineering as electrospun combinations with other polymers, synthetic or natural in origin. The use of electrospinning as a fabrication technique for gelatin-based nerve conduits is particularly advantageous because it allows the optimisation and manipulation of mechanical, biological, and kinetic properties. In particular, electrospinning allows control over the orientation of the nanofibres, which is a key component in the creation of a functional scaffold [65]. Fig. 3 offers a simple overview of the structure of as nerve conduit focusing in its three crucial parts: oriented substratum achieved through electrospinning, seeded support cells, and controlled release of NGF. 3D electrospun nanofibrous gelatin conduits allowed differentiation of motor neuron-like cells, showing great potential for applications in the CNS [66, 67]. The most common combination of hybrid polymer conduits is gelatin/PCL. Gelatin combined with PCL acted as a positive cue to support neurite outgrowth and allowed culture and proliferation of Schwann cells in vitro [68-70] and, more recently, a PCL/collagen blend incorporated into a gelatin matrix was used to bridge a $15 \mathrm{~mm}$ gap in sciatic nerve in rats [71]. Gelatin has also been successfully blended and electrospun with PLA, increasing differentiation into motor neurons lineages and promoting neurite outgrowth [72].

Gelatin is often crosslinked with genipin, a non-toxic crosslinker for proteins which enhances both biocompatibility and stability of the crosslinked product. An interesting application involved electrospun gelatin scaffolds crosslinked with genipin as a platform to provide biochemical cues to seeded cells in a decellularised rat brain ECM. This novel approach showed biocompatibility, cytocompatibility, and differentiative potential, providing tissue-specific signals aimed at expressing neural precursor cells [27]. Yang et al. developed a biodegradable nerve guide conduit containing gelatin crosslinked with genipin and tri-calcium phosphate ceramic particles for peripheral nerve regeneration. The conduit was tested on a short gap, $10 \mathrm{~mm}$, in rat sciatic nerve, but it showed increased motor functionality and histomorphometric assessments confirmed its superiority over silicone tubes [73, 74].

Recently, gelatin nanoparticles have been used to enhance the biocompatibility of polymeric scaffolds for neural tissue engineering. For example, gelatin coated nanoparticles contained in cellulose acetate/PLA scaffolds showcased higher cell viability than uncoated 


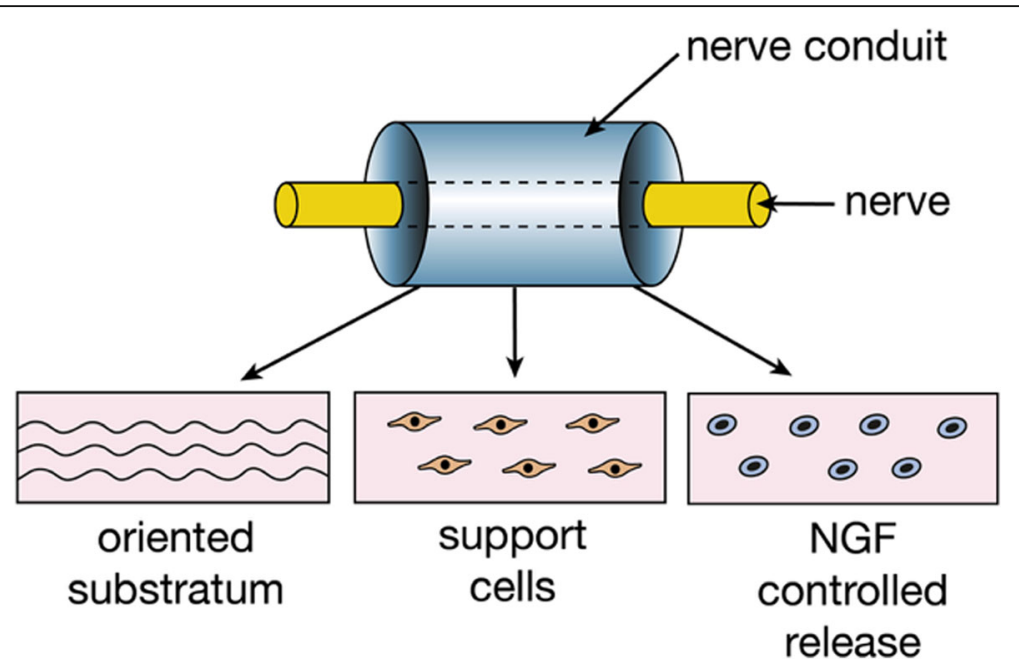

Fig. 3 Polymeric nerve conduit. Components of a polymeric nerve conduit, oriented substratum, support cells, and controlled release of a neural growth factor

scaffolds and they acted as a nerve guidance conduit for sciatic nerve defects in vitro and in vivo [75] while a gelatin/chitosan/PEDOT hybrid scaffold enhanced neurite growth of PC12 cells and promoted neuron-like cell adhesion and proliferation [76].

In addition, gelatin hydrogels have been used as a printable bioink for advanced bioprinting. Zhu et al. combined a gelatin/methacrylamide hydrogel with graphene nanoplatelets as a novel bioink and the printed neural constructs exhibited well-defined architecture, homogenous cell distribution, and neuronal differentiation [77]. The same research group combined this technology with low level light therapy which exhibited positive effects on the rehabilitation of degenerative nerves and neural disorders [78].

\section{Elastin}

Elastin-based biomaterials are attracting a lot of interest for tissue engineering applications due to their remarkable properties. Elastin is a structural protein characterised by elasticity, self-assembly, long-term stability, and biological activity. Elastin is an ECM protein that provides elasticity to tissues and organs, therefore it is most abundant in organs where elasticity is a key aspect, such as blood vessels, elastic ligaments, lungs, and skin [79]. Clearly, incorporation of elastin in biomaterials is majorly significant when the elasticity effects can be exploited, hence its most popular applications are for soft tissue regeneration, such as skin and blood vessels [80, 81].

However, elastin-like polypeptides (ELPs) have found specialised applications in neural tissue engineering. ELPs enhance the biocompatibility and stability of polymeric structures and, due to their tuneable characteristics, act as robust drug delivery systems targeting the brain. For example, ELPs can be tailor made to be thermally responsive and passively target specific areas of the CNS for treatment of neurodegenerative disorders [82]. ELPs fused with neurotrophin served as a drug depot, limiting neurotrophin loss due to diffusion, and allowed controlled spatio-temporal drug delivery [83]. Moreover, the tuneable characteristics of ELPs allowed intranasal administration aimed at therapeutic delivery of drugs to the CNS [84].

Elastin is not widely used in neural tissue engineering, but ELPs have been recently investigated for novel drug delivery systems and they have found promising applications for thermal inhibition of neurodegenerative disorders. Therefore, it is conceivable that elastin has found its niche role in neural tissue engineering and its applications could expand to include different devices and regeneration strategies.

\section{Hyaluronic acid}

Hyaluronic acid (HA) is a glycosaminoglycan found in extracellular tissues in various parts of the human body, where it plays a crucial role in lubrication. HA has been investigated at length for tissue engineering purposes due to its tuneable properties including biodegradability, biocompatibility, bioresorbability, and hydrogel forming ability [85].

HA has found widespread success in neural tissue engineering, supporting neurite outgrowth, differentiation, and proliferation on different substrates. HA hydrogels enhance the survival rates and proliferation of neural precursors, holding great promise for peripheral nerve regeneration therapies [86, 87] and therapeutic approaches to the CNS $[32,88,89]$ In particular, HA hydrogels have suitable mechanical properties that 
influence the differentiation of neural progenitors, opening a new path for therapies targeting neurodegenerative diseases $[21,90]$.

HA can be combined with other natural biopolymers, especially collagen due to the similar nature of the two biomaterials. For instance, Zhang et al. used neural stem cells embedded in a $\mathrm{HA} /$ collagen conduit to promote the regeneration of a $5 \mathrm{~mm}$ facial nerve gap in rabbits [91]. Combinations of HA and chitosan have also been successful in peripheral nerve regeneration. $\mathrm{Li}$ et al treated peripheral nerve crush injury in a rat model using chitosan conduits combined with $\mathrm{HA}$ [41], and $\mathrm{Xu}$ et al. used an injectable chitosan/HA biodegradable hydrogel for the regeneration of peripheral nerve injury [92]. Further, blends of HA and biodegradable synthetic polymers, such as PLGA and poly-L-lysine, showed great potential for controlled delivery of drugs aimed at axonal regrowth after spinal cord injury in vitro [93] and in vivo [94].

The high biocompatibility of HA has been invaluable to decrease the inflammatory response generated by electroconductive polymers in neural tissue engineering. For example, HA nanoparticles doped with PEDOT have been incorporated into a chitosan/gelatin scaffold, showing great PC12 cell adhesion and growth [95], and pyrrole/HA conjugates demonstrated considerable potential to mask conducting electrodes from adverse glial response upon implantation [96].

\section{Alginate}

Alginate is a naturally occurring anionic biopolymer usually obtained from brown seaweed. Alginate has found growing interest in tissue engineering due to its biocompatibility, low toxicity, low-cost, and gelation characteristics [97]. However, one of the key disadvantages of alginate is the natural presence of impurities, such as heavy metals, endotoxins, proteins, and polyphenolic compounds, attributable to its marine origin. Therefore, alginate has to be purified in a multi-step extraction procedure to a very high purity in order to minimise possible adverse effects, including immunogenic or inflammatory responses, upon implantation [97].

Alginate has been used in various biomedical applications, such as drug and protein delivery, wound healing, and as a substrate for cell culture. Alginate gels were also found to be particularly useful for tissue engineering, promoting the regeneration of blood vessels, bones, cartilage, muscle, pancreas, liver, and peripheral nerves.

Suzukia et al., a Japanese research group, investigated at length the use of alginate in neural tissue engineering. Their studies showed that alginate gels promote peripheral nerve regeneration across a long gap, $50 \mathrm{~mm}$, in cat sciatic nerve [98] and a $10 \mathrm{~mm}$ nerve gap in rats, increasing the diameter of the regenerating axons [99]. The group also tested an alginate sponge for the repair of facial nerves in cats. The facial nerve repaired with alginate showed remarkable regeneration but the group notably reduced the size of the nerve defect to $5 \mathrm{~mm}$ [100]. Further, alginate sponges implemented to regenerate cavernous nerves in rats showed exceptional regeneration and restoration of erectile function [101], and they also successfully enhanced elongation of regenerating axons in the spinal cord of young rats [102], albeit both researches considered a very small gap $(2 \mathrm{~mm})$.

Suzukia et al. also showed how non-tubulation repair using alginate has no significant differences for peripheral nerve injury regeneration compared to its tubulation counterpart on a cat model and it can be used as a regenerative approach [103]. These findings were confirmed by Hashimoto et al. who showed no electrophysiological or morphological differences between alginate tubular and non-tubular structures used for nerve regeneration [104].

Alginate has been recently used to create scaffolds for neural applications. Usually, hybrid scaffolds combine the biological characteristics of alginate with the mechanical properties of other biopolymers, both natural and synthetic in origin such as HA or PVA, showing great potential for peripheral nerve regeneration [105-107]. The leading application of alginate in neural tissue engineering is the treatment of spinal cord injury in rats, where it has been continuously successful in regenerating small nerve gaps, ranging from 2 to $4 \mathrm{~mm}$ [108-111].

\section{Chitosan}

Chitosan is a linear polysaccharide derived by the chemical deacetylation of chitin, the major structural polysaccharide found in crustaceans and shellfish. Chitosan has very interesting properties, such as gel forming capabilities, high adsorption capacity, and biodegradability. Chitosan is extremely biocompatible and non-cytotoxic, as well as presenting antibacterial, antifungal, and antitumor activity [112]. In addition, chitosan is a versatile biopolymer easily processed into sponges, gels, membranes, beads, and scaffolds, therefore it can be tailor made to suit a specific application.

Chitosan hydrogels have been consistently successful in neural tissue engineering, exhibiting cell adhesion, cell interaction, cell survival, and neurite outgrowth [76, 113, 114]. Further, 3D porous chitosan scaffolds combined with NGF had a synergistic effect on the differentiation of neural stem cells and showed potential to regenerate damages in both CNS $[115,116]$ and PNS $[117,118]$.

Often, chitosan is used to enhance the biocompatibility of synthetic polymers with better mechanical characteristics. For example, chitosan was used to increase the biocompatibility of PVA in nanofibrous scaffolds, enhancing viability and proliferation of PC12 cells in vitro [26], and 
in PVA/SWCNTs structures, increasing the in vitro proliferation rate and integration of human derived brain cells U373 [119]. Aligned PCL/chitosan fibres supported PC12 cells adhesion and growth, enhancing neurite extension along the fibre orientation [120]. PLGA/chitosan scaffolds guided neuronal differentiation for peripheral nerve regeneration both in vitro and in vivo [121, 122].

In addition, chitosan can be chemically modified with ease, thanks to its ability to absorb cell-adhesive molecules, such as collagen, fibronectin, laminin, and genipin. These molecules react with the proteins on the surface of Schwann cells and support their attachment and proliferation, showing potential in directing peripheral nerve regeneration [123-125].

Chitosan micro/nano vehicles have also been successfully developed to deliver antitumor drugs, growth factors, and pharmaceutical medications to the CNS. For example, Skop et al. designed and optimised biocompatible chitosan microspheres for the delivery of neural stem cells and growth factors for CNS injuries [126] while Elnaggar et al. designed chitosan particles loaded with the drug piperine, reported to have neuroprotective potential against Alzheimer's Disease, which successfully targeted specific areas of the brain [34]. Chitosan nanoparticles have also been developed for intranasal delivery of therapeutic agents to the brain $[127,128]$.

Chitosan has found recent application as a novel bioink for neural applications and 3D printing of neural constructs. $\mathrm{Gu}$ et al. developed a combination of extruded chitosan, alginate, and agarose to form a bioink seeded with front cortical human neural stem cells. Immediately after printing $25 \%$ of the seeded cells died, but the cells proliferation continued and, after three weeks, immunohistochemical analysis showed signs of mature neurons [129].

\section{Keratin}

Keratin protein is a polypeptide composed of different amino acids with intermolecular bonding of the disulphide cysteine amino acid and inter and intra-molecular bonding of polar and non-polar acids. Keratin has demonstrated great potential as a biomaterial and it has a long history of applications in the biomedical field due to its high performance biological functionalities. Keratin's ability to create suitable substrates and bioscaffolds is linked to its optimal biodegradability, biocompatibility, and non-immunogenicity. Keratin also facilitates good cell adhesion and proliferation through its biological characteristics and its versatile amino acid structure can be easily modified to suit a particular tissue [130].

Keratin was one of the first biomaterials to show promise for neural tissue engineering, due to its biological activities which facilitated the proliferation and infiltration of Schwann cells [131]. Keratin has found widespread application in the treatment of peripheral nerve injuries. In particular, keratin hydrogels can build biocompatible structures that facilitate neural cell adhesion and axonal ingrowth, while being reliably biodegradable. Multiple studies showed how keratin hydrogels promote the rapid regeneration of peripheral nerves in vivo, enhancing the activity, attachment, and proliferation of Schwann cells. Keratin hydrogels have the potential to be used clinically to improve conduits repair, producing long-term electrical and histological results equivalent to sensory nerve autograft. However, some of these older studies [132, 133] only considered small nerve gaps $(4 \mathrm{~mm})$.

Recent studies have tried to bridge a more significant nerve gap. For example, Lin et al. have developed a keratin hydrogel that, in combination with PCL nerve guides, allowed the group to bridge a $15 \mathrm{~mm}$ sciatic nerve injury in a rat model, promoting Schwann cell and axon migration [134]. Hill et al. used keratin hydrogel scaffolds to bridge a considerable gap of $2 \mathrm{~cm}$ in a rabbit model, and, although the keratin conduits were not as successful as nerve autografts, they induced a significant improvement in the overall recovery [135]. Pace et al. used a keratin nerve conduit luminal filler to bridge a $1 \mathrm{~cm}$ nerve gap in primates, demonstrating the effectiveness of keratin as a biomaterial for nerve regeneration when confronted with a saline-treated control group [136].

Keratin can be easily electrospun in combination with other non-natural polymers with stronger mechanical characteristics, enhancing their biocompatibility with excellent results. Electrospun keratin fibres consistently showed good biocompatibility, cell attachment, proliferation, and viability. In neural tissue engineering, an electrospun PVA/keratin nanofibrous scaffold allowed glial cells adhesion, proliferation, and viability in vitro, confirming the optimal results seen in other tissue engineering fields [137].

\section{Silk}

Silk is a fibrous structural protein produced by silkworms and spiders with unique properties suitable for a biomaterial. Silk shows great mechanical strength, excellent biocompatibility, minimal immunogenicity, limited bacterial adhesion, and controllable biodegradability [138]. Further, silk is a versatile material that has been used for the fabrication of biomimetic structures, such as films, hydrogels, scaffolds, nanofibres, and nanoparticles.

Kaplan's intensive research on silk has uncovered novel applications for neural tissue engineering [30, 39, 139]. In particular, silk hydrogels are soft and sustainable biomaterials often used in neural tissue engineering due to their ability to maintain structural integrity more than other biomaterials, such as fibrin and collagen gels, while 
being able to elicit increased axonal bundling. Silk hydrogels have been successfully developed as functional scaffolds to support the differentiation of neurons for the regeneration of brain and nerve tissue [30, 139, 140]. Silk hydrogels can also be chemically modified with bioactive peptides, such as IKVAV, that increased cell viability and enhanced neural differentiation [141]. Further, silk hydrogels showed potential for 3D bioprinting of functional nerve tissue, characterised by high resolution, low feature size, reproducibility, and long term cell viability [142].

Silk fibroin showed good biocompatibility and absence of cytotoxic effects in vitro, and it can act as tissue engineered nerve guide for potential treatment of CNS injuries. For example, Benfenati et al. developed silk fibroin films that supported neurite outgrowth and preserved neuronal functions, such as the intracellular $\mathrm{Ca}^{2+}$ concentration response to a noxious stimulus [143]. Zhang et al. created a 3D silk fibroin scaffold with uniaxial channels that provided continuous contact guidance and regulated axonal elongation for the maturation of hippocampal neurons [144]. Recently, Gennari et al. developed a silk fibroin scaffold for in situ delivery of gamma-aminobutyric acid (GABA) and allopregnanolone (ALLO) showing strong Schwann cells attachment and neuronal survival [145].

Further, silk fibroin can be easily electrospun for nerve tissue engineering applications. For example, Tian et al. developed electrospun PLA/silk fibroin nanofibres embedded in NGF, that supported attachment and differentiation of PC12 cells [146]. Dinis et al. developed an electrospun silk-based nerve conduit with aligned and longitudinally oriented microchannels aimed at peripheral nerve regeneration. The nerve graft mechanical behaviors were comparable to those of rat sciatic nerves, showing a similar stress-strain behavior and tensile strength [39]. Xue et al. investigated the regenerative properties of an electrospun silk-fibroin scaffold in a long, $30 \mathrm{~mm}$, sciatic nerve lesion in dogs, showing results close to those achieved by autologous nerve graft [24]. Combinations of silk and electroconductive polymers also demonstrated potential for peripheral nerve regeneration. Das et al. fabricated an electrospun PANi/silk conduit that showed excellent biocompatible and electrophysiological parameters after 12 months of implantation in rats, exhibiting cellular recruitment and thick lamellar deposition of myelin over regenerating axons [40]. Silk/CNTs composite scaffolds have consistently shown excellent results in neural tissue engineering, promoting neural differentiation and serving as an efficient supporting matrix for the regeneration of nerve tissue $[147,148]$.

In addition, silk coating around brain-penetrating electrodes reduced glial scarring in the CNS, allowing the implantation of electrodes for electrophysiological recording and local stimulation in vivo, used for diagnostic and therapeutic purposes $[149,150]$.
Spider silk is less used in neural tissue engineering mainly due to difficulties in retrieving the material, but its application in vitro has been successful. For example, Roloff et al. used spider silk as a guidance conduit for human model neurons, inducing the formation of ganglion-like cell structures in four weeks [151], while Lewicka et al. developed a spider silk matrix that provided an optimal microenvironment for neural stem cells cultures [152].

\section{Synthetic polymers for neural tissue engineering}

Synthetic polymers used for neural applications can be either biodegradable or non-biodegradable. Polyesters of lactic and glycolic acid, PLA, PGA, and their co-polymer PLGA, are considered biodegradable, like hydrogels based on polyethylene glycol, PEG, whereas biomaterials containing methacrylate are usually non-biodegradable. Initially, neural scaffolds were made of the same materials used for surgical repairs of peripheral nerves and skin grafting [49]. However, due to advances in biomaterials chemistry and technology, new matrices have been created that better suit the neural environment [153]. Nowadays neural scaffolds are principally highly aqueous hydrogels, soft polymers that share various similarities and properties with the nerve tissue, and present a strong versatility, which allows their chemistry and architecture to be adjusted according to a specific need $[109,135,139]$. Functionalization of synthetic polymers through surface modification techniques and inclusion of neurotrophic factors expanded the use of synthetic scaffolds to drug delivery and gene delivery vehicles to the CNS [154-156].

The use of synthetic or non-natural polymers in neural tissue engineering is advantageous because of their mechanical strength and flexibility combined with ease of modification and tailorability, as their structural properties can be modified in many ways, including blending and copolymerization. Synthetic polymers are also compatible with numerous fabrication techniques, such as wet-spinning, freeze-drying, and electrospinning. However, there are inherent problems with the use of synthetic polymers. Despite synthetic polymers being mainly non-toxic, there are still concerns regarding toxic residual monomers from incomplete polymerisation as well as degradation products and plasticisers. Therefore, synthetic polymers require intensive and comprehensive testing prior to translation into the clinic. The main synthetic polymers used in neural tissue engineering have been summarized in Table 2 along with their applications.

\section{Synthetic polymers}

Poly ( $\alpha$-hydroxy acid) polymers such as poly(lactic acid), (PLA), poly(glycolic acid), (PGA), and their copolymer poly(lactic-co-glycolic acid), (PLGA), have been used as 
Table 2 The main synthetic polymers used in neural tissue engineering, biocompatibility in vitro/in vivo, and examples of their applications

\begin{tabular}{|c|c|c|c|c|}
\hline $\begin{array}{l}\text { Synthetic } \\
\text { Polymer }\end{array}$ & $\begin{array}{l}\text { Biocompatibility } \\
\text { in vitro }\end{array}$ & $\begin{array}{l}\text { Biocompatibility } \\
\text { in vivo }\end{array}$ & Application & Reference \\
\hline \multicolumn{5}{|c|}{ Preclinical Studies } \\
\hline \multirow[t]{2}{*}{ PLA } & Rat SCs & & $\begin{array}{l}\text { Nanofibrous } \\
\text { conduit }\end{array}$ & [159] \\
\hline & NSCS & & $\begin{array}{l}\text { Nanofibrous } \\
\text { conduit }\end{array}$ & {$[162,163]$} \\
\hline \multirow[t]{4}{*}{ PLGA } & U87 & & Microparticles & {$[36]$} \\
\hline & & Dogs & Nerve conduit & [122] \\
\hline & DRGs & Rats & Scaffold & [164] \\
\hline & & Rats & Microparticles & [166] \\
\hline \multirow[t]{5}{*}{ PEG } & NPCs & & Hydrogel & [169-171] \\
\hline & & Rats & Hydrogel & [171] \\
\hline & & Rats & $\begin{array}{l}\text { Intravenous } \\
\text { administration }\end{array}$ & {$[172,173]$} \\
\hline & $\begin{array}{l}\text { Guinea pig } \\
\text { spinal cord } \\
\text { injury model }\end{array}$ & & pure PEG & [174] \\
\hline & & Rats & Scaffold & {$[175]$} \\
\hline \multirow[t]{2}{*}{ PHEMA } & & Rats & $\begin{array}{l}\text { Hydrophilic } \\
\text { sponge }\end{array}$ & [176] \\
\hline & PC12 & & Hydrogel & [179] \\
\hline
\end{tabular}

PLA: polylactic acid; PLGA: poly(lactic-co-glycolic acid); PEG: polyethylene glycol; pHEMA: poly(2-hydroxyethylmethacrylate); SCs: stem cells; NSCs: neural stem cells; DRGs: dorsal root ganglia; NPCs: neural progenitor cells.

biomaterials for a number of different biomedical applications focusing on neural tissue engineering. PLA and PGA are thermoplastic polymers characterized by polyesters links of, respectively, lactic or glycolic acid. Both PLA and PGA can be absorbed or hydrolyzed in vivo, and they are biodegradable. PLA and PGA were the first biopolymers trialed for regenerate studies using nervous tissue as they had been previously used as an absorbable suture material [157] and grafting material for wound healing [158].

PLA has been successfully used to design and construct scaffolds that provide support to Schwann cells, allowing elongation of axons, and to promote vascular growth [159]. However, PLA scaffolds have been found to be dimensionally or structurally unstable, often shattering and crumpling. Equally, PGA-based nanoconduits have excellent mechanical properties that favor their use in clinical settings, but it was demonstrated that they progressively lose their strength after 1-2 months upon implantation [160]. Due to their instable nature, in most cases PGA-based nanoconduits are limited to bridge a small nerve gap [161]. Based on these data, researches prefer to use PLA or PGA copolymers as they are more mechanically reliable.

PLA based multichannel conduits with a nanofibrous microstructure have been used to promote the differentiation of neural stem cells in mature neurons in vitro [162]. Despite the improved mechanical characteristics, the nanofibrous microstructure was still observed to degrade too fast and it had to be stabilized using a natural polymer, in particular through the use of a gelatin wrap [163].

PLGA has been used extensively in neural tissue engineering because its characteristics, including permeability, swelling, deformation, and degradation rate, can be controlled by altering the ratio of PLA:PGA to suit specific applications, especially drug delivery microparticles and conduits for nerve regeneration. For instance, multichannel PLGA scaffolds seeded with Schwann cells have been shown to have a synergistic effects on neural regeneration, albeit further studies are needed to aid functional recovery $[122,164]$. Further, PLGA seems to be extremely effective in transporting therapeutic agents across the $\mathrm{BBB}$. The inherent difficulties that the $\mathrm{BBB}$ represents as a protective layer has forced researchers to engineer multiple different approaches that attempt to deliver substantial quantities of drugs to specific parts of the brain. PLGA microspheres have shown potential to overcome this crucial issue and cross the BBB to deliver anti-tumor drugs $[36,165]$ and glial derived neurotrophic factor (GDNF) for the treatment of neurodegenerative diseases such as Parkinson's Disease [166].

Hydrogels are three-dimensional cross-linked hydrophilic polymer networks capable of swelling and de-swelling reversibly in water and can retain large volumes of liquid in a swollen state [167]. They can be designed to have controllable responses and shrink or expand according to the environment they are in [167]. In neural tissue engineering, the two most common polymers used to create synthetic hydrogels are polyethylene glycol (PEG) and poly (2-hydroxyethyl methacrylate); (pHEMA).

PEG is a biodegradable synthetic polymer of ethylene oxide (EO) units. PEG is highly biocompatible and well suited for use in hydrogels due to its hydrophilic properties, crucial for nutrient and waste transport, and is also biochemically inert. In addition, PEG is non-immunogenic and resistant to protein absorption. However, unlike natural polymers used in hydrogels, PEG is not bioactive, hence it is often used in combination with other polymers [168].

PEG hydrogels have been extensively used for neural tissue engineering. Neuronal cell growth on PEG platforms improve neural cell survival, proliferation, and differentiation, showing great potential for the treatment of CNS injuries [169-171]. Hydrogels can be designed and constructed in different shapes (2D or 3D), but the properties and attributes of the design seem to influence neuronal cells behavior more so in 3D cultures rather than 2D cultures. Lampe et al. showed that in PEG 2D cultures, hydrogel properties did not affect metabolic or apoptotic activity, but did impact cell proliferation and 
increased glial cell reactivity. Conversely, in PEG 3D cultures that closely matched the stiffness of the native brain, cells had increased metabolic activity and proliferation and lower rates of apoptosis [169].

The versatile and non-toxic nature of PEG meant it could be trialed preclinically and administered intravenously following head injury. After severe traumatic brain injury, intravenous administration of PEG dampened cerebral cell loss and slowed the degeneration of injured axons to the point that PEG-treated brains closely resembled those of uninjured animals [172, 173]. Further, PEG has shown promise following spinal cord injury, significantly accelerating and enhancing the membrane resealing process and restoring mechanical integrity following compression [174]. Liu et al. also showed enhanced cell growth and migration along with improved functional recovery in rats after transection of the spinal cord using an electrospun PLGA/PEG scaffold [175].

pHEMA, is a polymer that forms hydrogels in water due to its extremely hydrophilic nature, is biocompatible, and it can polymerise at low temperatures, (between $-20^{\circ} \mathrm{C}$ and $+10^{\circ} \mathrm{C}$ ), which allows immobilisation of proteins into hydrogels.

Initially, pHEMA was developed as a hydrophilic sponge, wherein porous hydrophilic sponges provide a stable three-dimensional scaffold capable of supporting and promoting axonal regeneration in rats [176]. Subsequently, Shoichet's group in Canada has development multiple pHEMA hydrogels capable of guiding neurite outgrowth. Figure 4 represent a simple schematic of an implanted hydrogel establishing new functional reconnections between seeded cells and the host's neurons. By controlling the formulation and surface chemistry, pHEMA hydrogels can be tailor made to suit a particular application in either the CNS or the PNS. For example, pHEMA hydrogel tubes have been manufactured with similar mechanical properties to those of the spinal cord, with a reported elastic modulus ranging between 200 and $600 \mathrm{kPa}$ [177]. Further, some pHEMA hydrogels were more suitable for peripheral nerve regeneration [178], and others have been developed with a photochemically bound nerve growth factor that promoted neurite outgrowth on 3D surfaces in vitro [179].

One of the main advantages of the use of hydrogels, both PEG and PHEMA, in neural tissue engineering is the variety of characteristics that can be achieved. They can be applied as nerve guidance conduits, intravenous inhibitors of cell death, and as 3D structures that support the formation of nervous tissue. The array of complex architectures that can be accomplished guarantees the ability to tailor each polymer to a specific application, mimicking the environment of the host tissue.

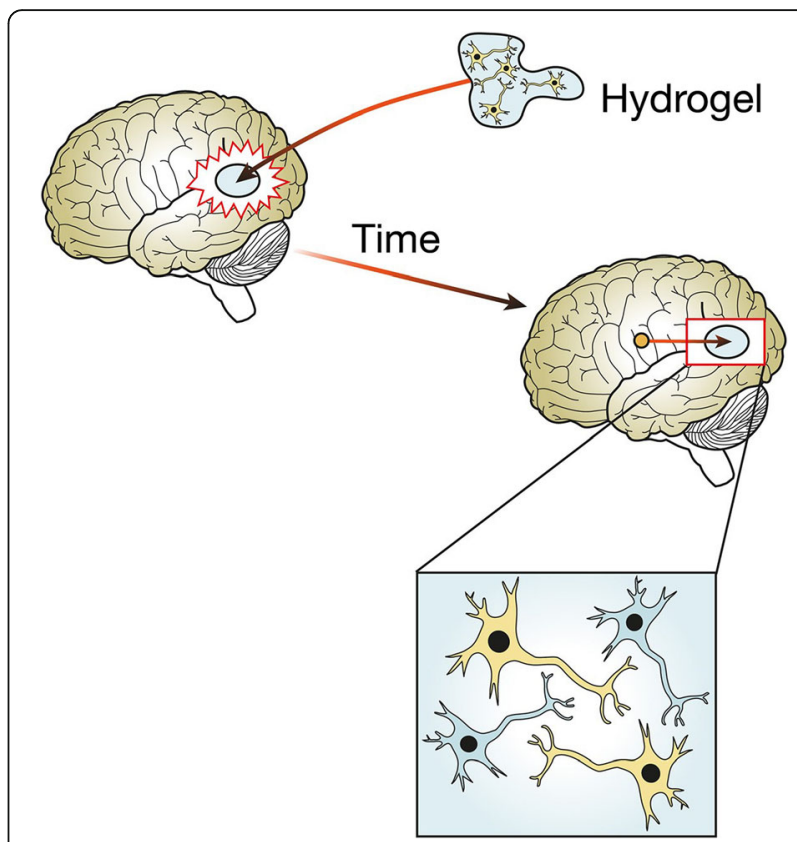

Fig. 4 Polymer hydrogel supports the regeneration of the brain tissue. Stroke causes reactive astrocytes to inhibit the regeneration of the brain tissue. A polymeric hydrogel seeded with neural cells is surgically implanted into the cavity caused by the stroke. With time, the reactive astrocytes are mitigated and the host's neurons can communicate with the cells seeded inside the hydrogel, reforming neural connections and restoring the original functions of the brain tissue

\section{Electrically conductive polymers}

The nervous system operates through a delicate network of electrical signaling in order for neurons to communicate with other cell types. Ideally, neural scaffolds should possess electrical properties to enhance proliferation and migration of neuronal cells [180]. Therefore, an electrically conductive polymer could ideally mimic the neural tissue and facilitate the reconstruction of neural connections.

Electrically conductive polymers have loosely held electrons along their backbones. In order to purposefully manipulate the electrical properties of conductive materials, they have to undergo a process called doping. The process of doping for conductive polymers usually include adding chemicals reactants to oxidize or reduce the systems so that electrons are pushed into the conductive orbital within the potentially conducting system. Electroconductive polymers have attracted attention in neural tissue engineering because of their tunable properties, including good stability, electrical conductivity, and ability to encapsulate and release molecules. Further, their electrical, chemical, and physical properties can be modified to suit a specific application. However, a critical issue in the use of conductive polymers as biomaterials for neural tissue engineering is suboptimal biocompatibility linked to their inability to degrade in 
vivo, which could induce chronic inflammation, and immunogenic reactions, requiring additional surgeries and treatments [181]. To overcome this issue, conductive polymers have been systematically blended with other biodegradable polymers, both synthetic and natural in origin, combining crucial electroconductive properties with more biologically favorable biomaterials. Table 3 . summarizes the main electrically conductive polymers used in neural tissue engineering and their applications.

Polypyrrole (PPy) is an organic polymer formed by the polymerization of pyrrole monomer and it is one of the most commonly used conductive polymers in neural tissue engineering. PPy is mainly used in combination with other biodegradable non-natural polymers such as PLA, PLGA, and PCL, in order to enhance its biocompatibility. For example, PPy-coated PLGA electrospun nanofibres combined the effect of electrical stimulation and topographical guidance that resulted in increased neurite growth [182]. Further, PPy-PLA fibres have been shown to enhance neurite adhesion, alignment, and elongation [19], whilst
PPy-PCL films has been shown to support cell proliferation and enhance neurite outgrowth through electrical stimulation both in vitro and in vivo [20]. Finally, a PPy-PDLLA nerve conduit has been used to repair sciatic nerve injury in rats, performing to the degree of the clinical gold standard in terms of functional recovery [183, 184]. PPy, combined with natural polymers, such as hyaluronic acid, has also been used to construct three dimensional electroconductive hydrogels aimed at improving recovery from traumatic brain injuries and stroke $[185,186]$.

One of the most interesting applications of PPy is its use as a new electrode material for long-term chronically implantable neuroprosthetics devices [187, 188]. Recently, PPy immersion in plasma has been shown to limit adverse immune reactions and favor direct tissue integration. Kondyurin et al. used this technique to create a biologically active electro-stimulating neural interface [189]. PPy has also found applications as an electrically controlled vehicle for localized drug delivery to the CNS [154, 190, 191].

Table 3 The main electroconductive polymers used in neural tissue engineering, biocompatibility in vitro/in vivo, and examples of their applications

\begin{tabular}{|c|c|c|c|c|}
\hline Electroconductive Polymer & Biocompatibility in vitro & Biocompatibility in vivo & Application & References \\
\hline \multicolumn{5}{|l|}{ Preclinical Studies } \\
\hline \multirow[t]{9}{*}{ PPy } & PC12 & & Electrospun nanofibers & {$[19,182]$} \\
\hline & PC12 & Rats & Films & [20] \\
\hline & PC12 & Rats & Nerve conduit & {$[183,184]$} \\
\hline & hNSCs & Rats & Hydrogel & $185,186]$ \\
\hline & PC12 & & Electrodes & [187] \\
\hline & $\begin{array}{l}\text { Auditory neurons from } \\
\text { Albino-Wistar rats }\end{array}$ & & Electrodes & [188] \\
\hline & $\begin{array}{l}\text { Primary murine cerebellar } \\
\text { glial culture }\end{array}$ & & Vehicle for drug delivery & [190] \\
\hline & PC12 & & Vehicle for drug delivery & [154] \\
\hline & & Rats & Vehicle for drug delivery & [191] \\
\hline \multirow[t]{5}{*}{ PANi } & PC12 & & Electrospun nanofibres & [193] \\
\hline & & Rats & Nerve conduit & {$[38,194]$} \\
\hline & NSCs & & Hydrogel & [195] \\
\hline & PC12 & & Hydrogel & [31] \\
\hline & & Rats & Electronic patch & [196] \\
\hline \multirow[t]{6}{*}{ PEDOT } & & Rats & Electrodes & {$[197,198]$} \\
\hline & & Mice & Electrodes & [46] \\
\hline & $\begin{array}{l}\text { Neurons from E18 Sprague- } \\
\text { Dawley cortices }\end{array}$ & & Electrodes & [199] \\
\hline & & Rats & Electrodes & {$[200,201]$} \\
\hline & ReNcell VM & & Substrate & [202] \\
\hline & P19 & & Substrate & [203] \\
\hline $\ln P$ & $\begin{array}{l}\text { Primary cell cultures from } \\
\text { hippocampal regions of rats }\end{array}$ & & Nanowire scaffolds & [204] \\
\hline
\end{tabular}


Polyaniline (PANi) is another useful conductive polymer that has many attractive properties, including high conductivity, easy synthesis, low cost, and easy availability [192]. Similar to PPy, a critical issue for the use of PANi in neural tissue engineering is its suboptimal biocompatibility. Therefore, PANi is often used in combination with more suitable biodegradable polymers, to mitigate inflammations or immunogenic reactions. For example, PANi/PLA-PCL electroactive electrospun fibres enhanced the NGF-induced neurite outgrowth of PC12 cells and showed great potential for nerve regeneration as an effective graft material [193]. Further, a research group in China has also successfully combined PANi with the natural biopolymer cellulose aiming at peripheral nerve regeneration, leading to possible clinical intervention for nerve injuries $[38,194]$.

Like PPy, PANi has been designed as a hydrogel material for neural tissue engineering. In particular, PANi hydrogels have been developed for peripheral nerve regeneration and as substrates for neural stem cells differentiation [31, 195]. In addition, PANi has recently showed promise as a biosensing electronic patch that could be integrated in electroresponsive tissues for recording and therapeutic stimulation, opening a new range of possible research trends for this material in neural tissue engineering [196].

Poly (3,4-ethylenedioxythiopene), (PEDOT), is an interesting electroconductive polymer characterised by optical transparency in its conductive state, high stability, and low redox potential. PEDOT has found numerous applications in neural tissue engineering, especially as a material for microelectrodes aimed at neural electrical stimulation and recording [46, 197, 198]. In particular, Cui's research group has developed numerous PEDOTbased electrodes for stable neural recording and therapeutic stimulation [199-201]. The use of PEDOT in neural tissue engineering has recently expanded to include neural stem cell differentiation through electrical stimulation, leading to longer neurite outgrowth and longer neurons [202, 203].

Furthermore, a recent study has shown that indium phosphide (InP) nanowire scaffolds influence neuronal and cell morphology, circuit formation, and function [204]. InP is a direct band semiconductor which is usually utilized for superior optoelectronic interfaces, and due to its conductive abilities, it is an effective physical cue for guided growth of neurites. This is the first work that showcases how neural cells can grow on InP-based optoelectronic substrates, proving its biocompatibility, and opening a new scenario for therapeutic approaches using electroconductive polymers [204].

\section{Carbon-based nanomaterials}

Carbon-based nanomaterials present exclusive electrical, mechanical, and biological characteristics, which make them particularly useful for tissue engineering. In particular, neural tissue engineering mainly utilizes graphene and carbon nanotubes because of their inherent properties of conductivity, flexibility, and biocompatibility. However, there is a substantial gap in our knowledge in terms of understanding the biological interactions of carbon-based nanomaterials in vivo. Therefore, further investigation is needed in order to explore interactions of carbon-based nanomaterials with singular cellular components and components of the immune system, as well as mapping the ultimate cycle of the materials in vivo, including accumulation, degradation, and/or excretion. Table 4 summarizes the uses of graphene and carbon nanotubes in neural tissue engineering.

Graphene is an allotrope of carbon consisting of a single layer of carbon atoms arranged in a 2-dimensional hexagonal lattice. It efficiently conducts heat and electricity, it is nearly transparent, bactericidal, and antiviral, and it is highly biocompatible with low cell toxicity. However, it should be noted that depending on whether graphene is used in $2 \mathrm{D}$ or $3 \mathrm{D}$, matrix cellular toxicity has been reported [205, 206], with 3D cultures being better for neural cell growth and proliferation. In addition, 3D graphene substrates are also able to encapsulate different nanoparticles, such as gold, increasing neuronal differentiation and guiding axonal alignment [35].

Graphene has been used for neural tissue engineering applications in numerous forms, particularly foams and graphene nanogrids. Rolled graphene foams have been developed as electrically conductive 3D scaffolds that stimulate and accelerate differentiation and proliferation of human neural stem cells [25, 207]. Akhvan's research showed that graphene nanogrids also increase the neural cell to glial cell ratio thanks to biocompatible stimulation techniques, including electrical, pulsed laser, flash photo, and near infra-red (NIR) laser stimulation [208-211]. Graphene has also found interesting applications as a material for neural probes, enhancing the quality of the neural-device interface [212].

Carbon nanotubes (CNTs) are allotropes of carbon with a cylindrical structure characterized by extraordinary thermal conductivity and optimal mechanical and electrical properties. CNTs are excellent candidates for neural tissue engineering due to their biocompatible, conductive, and non-biodegradable nature. Primarily, CNTs function as implants where long-term cues for neurite outgrowth are necessary, such as regeneration after spinal cord injury or brain injury [213]. Both single walled carbon nanotubes (SWCNTs) and multi walled carbon nanotubes (MWCNTs) have been used in neural tissue engineering. SWCNTs work as substrates that modulate and stimulate neural cells through the variation of conductance, for example using lateral currents for the purpose of healing neurological and brain related injuries [214]. SWCNTs substrates also 
Table 4 The main carbon-based nanomaterials used in neural tissue engineering, biocompatibility in vitro/in vivo, and examples of their applications

\begin{tabular}{|c|c|c|c|c|}
\hline Electroconductive Polymer & Biocompatibility in vitro & Biocompatibility in vivo & Application & References \\
\hline \multicolumn{5}{|l|}{ Preclinical Studies } \\
\hline \multirow[t]{6}{*}{ Graphene } & PC12 & & Sheets & [205] \\
\hline & BV2 cells & & Foam & [206] \\
\hline & NSCS & & Substrate & [35] \\
\hline & NSCs & & Rolled foam & {$[25,207]$} \\
\hline & hNSCs & & Nanogrids & [208-211] \\
\hline & & Rats and Mice & Electrode & [212] \\
\hline \multirow[t]{9}{*}{ CNTs } & NG108-15 & & SWCNTS & [213] \\
\hline & $\begin{array}{l}\text { Hippocampal neuronal cultures } \\
\text { from Sprague-Dawley rats }\end{array}$ & & SWCNTS & [215] \\
\hline & $\begin{array}{l}\text { Astrocytic cultures from } \\
\text { C57BL/6 mice pups }\end{array}$ & & SWCNTS & [216] \\
\hline & NSCS & & SWCNTS & [217] \\
\hline & NSCs & & MWCNTS & [218] \\
\hline & & Mice & MWCNTS & [219] \\
\hline & PC12 & & MWCNTS & [220] \\
\hline & PC12 & & Electrodes & [187] \\
\hline & & Rats & Electrodes & [221] \\
\hline
\end{tabular}

hNSCs: human neural stem cells; NCSs: neural stem cells; CNTs: carbon nanotubes; SWCNTs: single-walled carbon nanotubes; MWCNTs: multi-walled

carbon nanotubes.

promoted neurite outgrowth in vitro [215-217]. Conversely, MWCNTs, due to greater stability, have been applied to novel technologies such as 3D printing of scaffolds for peripheral nerve regeneration [218], and developed as neural guidance conduits and as targeted drug delivery vehicles to the CNS $[219,220]$.

Finally, CNTs-based electrodes have been developed for chronically implantable neural interfaces and recording of electrogenic cells [187, 221].

\section{Conclusion and future perspectives}

This review highlighted the most prominent polymeric biomaterials that demonstrated potential for neural tissue engineering. Given the degree of morbidity and lifelong impairments caused by injuries to the nervous system, both CNS and PNS, its functional restoration is critical. Current therapeutic approaches for damages to CNS and PNS are insufficient to restore the functions of the nervous system and new tissue engineering applications are needed. This review investigated the main polymers, both synthetic and natural, used in neural tissue engineering, focusing on their biocompatibility both in vitro and in vivo, key applications, and advantages/disadvantages between different kinds of polymers. Polymeric applications for neural tissue engineering continue to evolve rapidly, focusing in particular on biocompatible electroconductive materials, such as PPy and PANi. The use of growth factors, neural progenitor cells, and neural stem cells combined with biopolymeric structures has improved the restoration capacities of polymeric biomaterials as well as their ability to target specific areas of the CNS and deliver therapeutic agents. Further advances in neural tissue engineering need to focus on innovative combinations of biopolymers and proteins, such as silk or keratin, which have shown great potential for new therapeutic and regenerative applications. Further, novel fabrication techniques are being explored and electrospinning has clearly emerged as an optimal candidate for neural tissue engineering, due to its ability to control the orientation of electrospun nanofibres, following the preferred directionality of neurite outgrowth. It is auspicious that continuous scientific research on promising natural polymers, regenerative strategies, and fabrication techniques will maximise the ability to functionally regenerate nervous tissues and restore electrochemical connections, unburdening society from the disastrous consequences of damages to CNS and PNS.

\footnotetext{
Abbreviations

ALLO: Allopregnanolone; BBB: Blood Brain Barrier; CNS: Central Nervous System; CNTs: Carbon Nanotubes; ECM: Extracellular Matrix; ELPS: Elastin-like polypeptides; GABA: Gamma-aminobutyric acid; GDNF: Glial Derived Neurotrophic factor; HA: Hyaluronic Acid; hNSCs: Human Neural Stem Cells; InP: Indium Phospide; NGF: Neural Growth Factor; PANi: Polyaniline; PCL: Polycaprolactone; PEDOT: Poly(3,4-ethylenedioxythiopene); PEG: Polyethylene glycol; PGA: Poly-glycolic acid; pHEMA: Poly(2-hydroxyethylmethacrylate); PLA: Poly-lactic acid; PLGA: Poly-lactic-co-glycolic Acid; PNS: Peripheral Nervous System; PPy: Polypirrole
} 


\section{Acknowledgements}

Not applicable.

\section{Funding}

The authors received no specific funding for this work.

\section{Availability of data and materials}

Not applicable.

\section{Authors' contributions}

RB wrote the manuscript with inputs from all the authors. $A A, A S$, and $A C$ revised the paper critically for important intellectual content. AC and $R B$ conceptualised the original images. AA and AC supervised the process. All authors read and approved the final manuscript.

\section{Ethics approval and consent to participate}

Not applicable.

\section{Consent for publication}

Not applicable.

\section{Competing Interests}

The authors declare that they have no competing interests.

\section{Publisher's Note}

Springer Nature remains neutral with regard to jurisdictional claims in published maps and institutional affiliations.

\section{Author details}

'Bioengineering Research Team, Centre for Bioengineering and Nanomedicine, Department of Food Science, University of Otago, PO Box 56 , Dunedin 9054, New Zealand. ${ }^{2}$ Department of Anatomy, Brain Health Research Centre and Brain Research New Zealand, University of Otago, PO Box 56, Dunedin 9054, New Zealand. ${ }^{3}$ BioMatter-Biomass Transformation Lab (BTL), École interfacultaire de Bioingénieurs (EIB), École polytechnique de Bruxelles, Université Libre de Bruxelles, Avenue F.D. Roosevelt, 50 - CP 165/ 61, 1050 Brussels, Belgium.

\section{Received: 14 August 2018 Accepted: 27 November 2018} Published online: 20 December 2018

\section{References}

1. Gomes ME, Rodrigeus MT, Domingues Rui MA, Reis Rui L. Tissue Engineering and Regenerative Medicine: New Trends and Directios_A Year in Review. Tissue Eng Part B Rev. 2017;23:3.

2. Lombardi WRM. New Challenges in CNS Repair: The Immune and Nervous Connection. Curr. Immunol Rev. 2012;8:87-93.

3. Li M, Zhao Z, Yu G, Zhang J. Epidemiology of Traumatic Brain Injury over the World: A Systematic Review. Austin Neurol \& Neurosci. 2016;1:2.

4. Bertram L, Tanzi RE. The genetic epidemiology of neurodegenerative disease. J Clin Invest. 2005;115:1449-57.

5. Checkoway H, Ludin Jl, Kelada SN. Neurodegenerative diseases. IARC Sci Publ. 2011;163:407-19.

6. Carmichael ST. Emergent properties of neural repair: elemental biology to therapeutic concepts. Ann Neurol. 2016;79:895-906.

7. Overman JJ, Clarkson AN, Wanner IB, Overman WT, Eckstein I, Maguire JL, Dinov ID, Toga AW, Carmichael ST. A role for ephrin-A5 in axonal sprouting, recovery, and activity-dependent plasticity after stroke. Proc Natl Acad. Sci. U S A. 2012;109:2230-9.

8. Schwab ME, Strittmatter SM. Nogo limits neural plasticity and recovery from injury. Curr. Opin. Neurobiol. 2014;27:53-60.

9. Benjamin EJ, Virani SV, Callway CW, Chamberlain AM, Chang AR, et al. Heart Disease and Stroke Statistics - 2018 Update: A Report From the American Heart Association. Circulation. 2018;137:67-492.

10. Siegel RL, Miller KD, Jemal A. Cancer statistics, 2018. CA Cancer J Clin. 2018; 68:7-30.

11. Sofroniew VM. Astrogliosis. Cold Spring Harb Perspect Biol. 2015;7:2.

12. Philips C, Cornelissen M, Carriel V. Evaluation methods as quality control in the generation of decellularized peripheral nerve allografts. J Neural Eng. 2018;15:2.
13. Cardoso Diogo C, Camassa JA, Pereira JE, Maltez da Costa L, Filipe V, Couto PA, Geuna S, Maurício AC, Varejão AS. The use of sheep as a model for studying peripheral nerve regeneration following nerve injury: review of the literature. Neurol Res. 2017;39:926-39.

14. Reichert PWW, Witkowski J, et al. Causes of secondary radial nerve palsy and results of treatment. Med Sci Monit. 2016;22:554-62.

15. Adiguzel E, Yasar E, Tecer D, Güzelküçük Ü, Taskaynatan MA, Kesikburun S, Özgül A. Peripheral nerve injuries: long term follow-up results of rehabilitation. Back Musculoskelet Rehabil. 2016;29:367-71.

16. Kouyoumdjian JA, Graça CR, Ferreira VF. Peripheral nerve injuries: A retrospective survey of 1124 cases. Neurol India. 2017;65:551-5.

17. Siemionow M, Brzezicki G. Chapter 8 "current techniques and concepts in peripheral nerve repair". International Review of Neurobiology. 2009;87(C):141-72

18. Johnson EO, Zoubos AB, Soucacos PN. Regeneration and repair of peripheral nerves. Injury. 2005;36S:24-9.

19. Zhou X, Yang A, Huang Z, Yin Z, Yin G, Pu X, Jin J. Enhancement of neurite adhesion, alignment and elongation on conductive polypyrrole-poly(lactide acid) fibers with cell-derived extracellular matrix. Colloids Surf B: Biointerfaces. 2017:149:217-25.

20. Durgam H, Sapp S, Deister C, Khaing Z, Chang E, Luebben S. Novel Degradable Co-polymers of Polypyrrole Support Cell Proliferation and Enhance Neurite Out-Growth with Electrical Stimulation. J Biomater Sci Polym Ed. 2012;21:1265-82.

21. Yang R, Xu C, Wang T, Wang Y, Wang J, Quan D, Deng DY. PTMAc-PEGPTMAC hydrogel modified by RGDC and hyaluronic acid promotes neural stem cells' survival and differentiation in vitro. RSC Adv. 2017;7:41098-104.

22. Huang CT, Shrestha LK, Ariga K, Hsu SH. A graphene-polyurethane composite hydrogel as a potential bioink for 3D bioprinting and differentiation of neural stem cells. J Mater Chem B. 2017;5:8854-64.

23. Gonzalez-Perez F, Cobianchi S, Heimann C, Philips JB, Udina E, Navarro X. Stabilization, Rolling, and Addition of Other Extracellular Matrix Proteins to Collagen Hydrogels Improve Regeneration in Chitosan Guides for Long Peripheral Nerve Gaps in Rats. Neurosurgey. 2017;80:465-74.

24. Xue C, Zhu H, Tan D, Ren H, Gu X, Zhao Y, Zhang P, Sun Z, Yang Y, Gu J, Gu $Y, G u X$. Electrospun silk fibroin-based neural scaffold for bridging a long sciatic nerve gap in dogs. J Tissue Eng Regen Med. 2017;12:1143-53.

25. Akhavan O, Ghaderi E, Shirazian SA, Rahighi R. Rolled graphene oxide foams as three-dimensional scaffolds for growth of neural fibers using electrical stimulation of stem cells. Carbon. 2016;97:71-7.

26. Alhosseini SN, Moztarzadeh F, Mozafari M, Asgari S, Dodel M, Samadikuchaksaraei A, Kargozar S, Jalali N. Synthesis and characterization of electrospun polyvinyl alcohol nanofibrous scaffolds modified by blending with chitosan for neural tissue engineering. Int J Nanomedicine. 2012;7:25-34.

27. Baiguera S, Del Gaudio C, Lucatelli E, Kuevda E, Boieri M, Mazzanti B, Bianco A, Macchiarini P. Electrospun gelatin scaffolds incorporating rat decellularized brain extracellular matrix for neural tissue engineering. Biomaterials. 2014;35:1205-14.

28. Cao J, Sun C, Zhao H, Xiao Z, Chen B, Gao J, Zheng T, Wu W, Wu S, Wang J, Dai J. The use of laminin modified linear ordered collagen scaffolds loaded with laminin-binding ciliary neurotrophic factor for sciatic nerve regeneration in rats. Biomaterials. 2011;32:3939-48.

29. Choi SK, Park JK, Lee SK, Jeon WB. Improved neural progenitor cell proliferation and differentiation on poly(lactide-co-glycolide) scaffolds coated with elastinlike polypeptide. J Biomed Mater Res B Appl Biomater. 2013;101:1329-39.

30. Bai S, Zhang W, Lu Q, Ma Q, Kaplan DL, Zhu H. Silk nanofiber hydrogels with tunable modulus to regulate nerve stem cell fate. J Mater Chem B. 2014;2:6590-600.

31. Guarino V, Alvarez-Perez MA, Borriello A, Napolitano T, Ambrosio L. Conductive PANi/PEGDA Macroporous Hydrogels For Nerve Regeneration. Adv Healthc Mater. 2013;2:218-27.

32. Horn EM, Beaumont M, Shu XZ, Harvey A, Prestwich GD, Horn KM, Gibson AR, Preul MC, Panitch A. Influence of cross-linked hyaluronic acid hydrogels on neurite outgrowth and recovery from spinal cord injury. J Neurosurg. 2007;6:133-40.

33. Namba RM, Cole AA, Bjugstad KB, Mahoney MJ. Development of porous PEG hydrogels that enable efficient, uniform cell-seeding and permit early neural process extension. Acta Biomater. 2009;5:1884-97.

34. Elnaggar YS, Etman SM, Abdelmonsif DA, Abdallah OY. Intranasal PiperineLoaded Chitosan Nanoparticles as Brain-Targeted Therapy in Alzheimer's Disease: Optimization, Biological Efficacy, and Potential Toxicity. J Pharm Sci. 2015;104:3544-56 
35. Kim TH, Lee KB, Choi JW. 3D graphene oxide-encapsulated gold nanoparticles to detect neural stem cell differentiation. Biomaterials. 2013; 34:8660-70.

36. Malinovskaya Y, Melnikov P, Baklaushev V, Gabashvili A, Osipova N, Mantrov S, Ermolenko Y, Maksimenko O, Gorshkova M, Balabanyan V, Kreuter J, Gelperina S. Delivery of doxorubicin-loaded PLGA nanoparticles into U87 human glioblastoma cells. Int J Pharm. 2017;542:77-90.

37. Wang C, Xu H, Liang C, Liu Y, Li Z, Yang G, Cheng L, Li Y, Liu Z. Iron Oxide @ Polypyrrole Nanoparticles as a Multifunctional Drug Carrier for Remotely Controlled Cancer Therapy with Synergistic Antitumor Effect. ACS Nano. 2013;7:6782-95.

38. Xu D, Fan L, Gao L, Xiong Y, Wang Y, Ye Q, Yu A, Dai H, Yin Y, Cai J, Zhang L. Micro-Nanostructured Polyaniline Assembled in Cellulose Matrix via Interfacial Polymerization for Applications in Nerve Regeneration. ACS Appl Mater Interfaces. 2016:8:17090-7.

39. Dinis TM, Elia R, Vidal G, Dermigny Q, Denoeud C, Kaplan DL, Egles C, Marin F. 3D multi-channel bi-functionalized silk electrospun conduits for peripheral nerve regeneration. J Mech Behav Biomed Mater. 2015;41:43-55.

40. Das S, Sharma M, Saharia D, Sarma KK, Muir EM, Bora U. Electrospun silkpolyaniline conduits for functional nerve regeneration in rat sciatic nerve injury model. Biomed Mater. 2017;12:4.

41. Li R, Liu H, Huang H, Bi W, Yan R, Tan X, Wen W, Wang C, Song W, Zhang Y, Hu M. Chitosan conduit combined with hyaluronic acid prevent sciatic nerve scar in a rat model of peripheral nerve crush injury. Mol Med Rep. 2018:17:4360-8.

42. Willerth SM, Sakiyama-Elbert SE. Approaches to Neural Tissue Engineering Using Scaffolds for Drug Delivery. Adv Drug Deliv Rev. 2007:30:325-38.

43. Ai J, Kiasat-Dolatabadi A, Ebrahimi-Barough S, Ai A, Lotfibakhshaiesh N, Norouzi-Javidan A, Sabero H, Arjmand B, Agayan HR. Polymeric Scaffolds in Neural Tissue Engineering: a Review. Arch Neurosci. 2014;1:15-20.

44. Elzoghby AO, Freag MS, Elkhodairy KA. Biopolymeric Nanoparticles for Targeted Drug Delivery to Brain Tumors. In: Kesharwani P, Gupta U, editors. Nanotechnology-Based Targeted Drug Delivery Systems for Brain Tumors. Cambride: Academic Press; 2018. p. 169-90.

45. Saraiva C, Praça C, Ferreira R, Santos T, Ferreira L, Bernardino L. Nanoparticlemediated brain drug delivery: Overcoming blood-brain barrier to treat neurodegenerative diseases. J Control Release. 2016;235:34-47.

46. Castagnola V, Descamps E, Lecestre A, Dahan L, Remaud J, Nowak LG, Bergaud C. Parylene-based flexible neural probes with PEDOT coated surface for brain stimulation and recording. Biosens Bioelectron. 2015;67:450-7.

47. Deng M, Yang X, Silke M, Qiu W, Xu M, Borghs G, Chen H. Electrochemical deposition of polypyrrole/graphene oxide composite on microelectrodes towards tuning the electrochemical properties of neural probes. Sens Actuators B Chem. 2011;158:176-84

48. Kulkarni VS, Butte KD, Rathod SS. Natural Polymers - a Comprehensive Review. IJRPBS. 2012;3:1597-613.

49. Madigan NN, McMahon S, O'Brien T, Yaszemski MJ, Windebank AJ. Current tissue engineering and novel therapeutic approaches to axonal regeneration following spinal cord injury using polymer scaffolds. Respir Physiol Neurobiol. 2009;169:183-99.

50. Sherman VR, Yang W, Meyers MA. The materials science of collagen. J Mech Behav Biomed Mater. 2015;52:22-50.

51. Archibald SJ, Shefner J, Krarup C, Madison RD. Monkey median nerve repaired by nerve graft or collagen nerve guide tube. J Neurosci. 1995;15:4109-23.

52. Mackinnon SE, Dellon AL. A Study of Nerve Regeneration Across Synthetic (Maxon) and Biologic (Collagen) Nerve Conduits For Nerve Gaps Up to 5 Cm in the Primate. J Reconstr Microsurg. 1990;6:117-21.

53. Yao Y, Cui Y, Zhao Y, Xiao Z, Li X, Han S, Chen B, Fang Y, Wang P, Pan J, Dai J. Effect of longitudinally oriented collagen conduit combined with nerve growth factor on nerve regeneration after dog sciatic nerve injury. J Biomed Mater Res B. 2017;106:6.

54. Kiyotani T, Teramachi M, Takimoto $Y$, Nakamura T, Shimizu $Y$, Endo K. Nerve regeneration across a $25-\mathrm{mm}$ gap bridged by a polyglycolic acid-collagen tube: a histological and electrophysiological evaluation of regenerated nerves. Brain Res. 1996;740:66-74.

55. Wangensteen KJ, Kalliainen LK. Collagen Tube Conduits in Peripheral Nerve Repair: A Retrospective Analysis. Hand. 2010;5:273-7.

56. Bozkurt A, Claeys KG, Schrading S, Rödler JV, Altinova H, Schulz JB, Weis J, Pallua N, van Nerveen SGA. Clinical and biometrical 12-month follow-up in patients after reconstruction of the sural nerve biopsy defect by the collagen-based nerve guide Neuromaix. Eur J Med Res. 2017;22:34.
57. Ceballos D, Navarro X, Dubey N, Wendelschafer-Crabb G, Kennedy WR, Tranquillo RT. Magnetically Aligned Collagen Gel Filling a Collagen Nerve Guide Improves Peripheral Nerve Regeneration. Exp Neurol. 1999;158:290-300.

58. Dubey N, Letourneau PC, Tranquillo RT. Guided Neurite Elongation and Schwann Cell Invasion into Magnetically Aligned Collagen in Simulated Peripheral Nerve Regeneration. Exp Neurol. 1999;158:338-50.

59. Eguchi Y, Ogiue-Ikeda M, Ueno S. Control of orientation of rat Schwann cells using an 8-T static magnetic field. Neurosci Lett. 2003;351:130-2.

60. Benjakul S, Nalinanon S, Shahidi F. Fish Collagen. In: Simpson BK, editor. Food Biochemistry and Food Processing. Oxford, UK: Wiley-Blackwell; 2012. p. 365-87.

61. Yamada S, Yamamoto K, Ikeda T, Yanagiguchi K, Hayashi Y. Potency of Fish Collagen as a Scaffold for Regenerative Medicine. Biomed Res Int. 2014;,vol 2014(Article ID 302932):8.

62. Elango J, Zhang J, Bao B, Palaniyandi K, Wang S, Wu W, Robinson JS. Rheological, biocompatibility and osteogenesis assessment of fish collagen scaffold for bone tissue engineering. Int J Biol Macromol. 2016;91:51-9.

63. Liu C, Sun J. Potential Application of Hydrolyzed Fish Collagen for Inducing the Multidirectional Differentiation of Rat Bone Marrow Mesenchymal Stem Cells. Biomacromolecules. 2014;15:436-43.

64. Su K, Wang C. Recent advances in the use of gelatin in biomedical research. Biotechnol Lett. 2015;37:2139-45.

65. Sill TJ, van Recum HA. Electrospinning: Applications in drug delivery and tissue engineering. Biomaterials. 2008;29:1989-2006.

66. Faghihi F, Mirzaei E, Ai J, Lotfi A, Sayahpour FA, Barough SE, Joghataei MT. Differentiation Potential of Human Chorion-Derived Mesenchymal Stem Cells into Motor Neuron-Like Cells in Two- and Three-Dimensional Culture Systems. Mol Neurobiol. 2016;53:1862-72.

67. Büyüköz M, Erdal E, Altinkaya SA. Nanofibrous gelatine scaffolds integrated with nerve growth factor-loaded alginate microspheres for brain tissue engineering. J Tissue Eng Regen Med. 2018;12:707-19.

68. Ghasemi-Mobarakeh L, Prabhakaran M, Morshed M, Nasr-Esfahani MH, Ramakrishna S. Electrospun poly( $\varepsilon$-caprolactone)/gelatin nanofibrous scaffolds for nerve tissue engineering. Biomaterials. 2008;29:4532-9.

69. Gupta D, Venugopal J, Prabhakaran MP, Giri Dev VR, Low S, Choon AT, Ramakrishna S. Aligned and random nanofibrous substrate for the in vitro culture of Schwann cells for neural tissue engineering. Acta Biomater. 2009;5:2560-9.

70. Alvarez-Perez MA, Guarino V, Cirillo V, Ambrosio L. Influence of gelatin cues in $\mathrm{PCL}$ electrospun membranes on nerve outgrowth. Biomacromolecules. 2010;11:2238-46.

71. Kriebel A, Hodde D, Kuenzel T, Engels J, Brook G, Mey J. Cell-free artificial implants of electrospun fibres in a three-dimensional gelatin matrix support sciatic nerve regeneration in vivo. J Tissue Eng Regener Med. 2017;11:3289-304

72. Binan L, Tendey C, De Crescenzo G, El Ayoubi R, Ajji A, Jolicoeur M. Differentiation of neuronal stem cells into motor neurons using electrospun poly-l-lactic acid/gelatin scaffold. Biomaterials. 2014;35:664-74.

73. Yang YC, Shen CC, Huang TB, Chang SH, Cheng HC, Liu BS. Characteristics and biocompatibility of a biodegradable genipin-cross-linked gelatin/ $\beta$ tricalcium phosphate reinforced nerve guide conduit. J Biomed Mater Res part B: Appl Biomater. 2010;95:207-17.

74. Yang YC, Shen CC, Cheng HC, Liu BS. Sciatic nerve repair by reinforced nerve conduits made of gelatin-tricalcium phosphate composites. J Biomed Mater Res part A. 2011:96:288-300.

75. Naseri-Nosar M, Salehi M, Hojjati-Emami S. Cellulose acetate/poly lactic acid coaxial wet-electrospun scaffold containing citalopram-loaded gelatin nanocarriers for neural tissue engineering applications. Int J Biol Macromol. 2017:103:701-8

76. Wang S, Sun C, Guan S, Li W, Xu J, Ge D, Zhuang M, Liu T, Ma X. Chitosan/ gelatin porous scaffolds assembled with conductive poly(3,4ethylenedioxythiophene) nanoparticles for neural tissue engineering. Journal of Mater Chem B. 2017:5:4774-88.

77. Zhu W, Harris BT, Zhang LG. Gelatin methacrylamide hydrogel with graphene nanoplatelets for neural cell-laden 3D bioprinting. Conf Proc IEEE Eng Med Biol Soc. 2016:4185-8.

78. Zhu W, George JK, Sorger VJ, Zhang LG. 3D printing scaffold coupled with low level light therapy for neural tissue regeneration. Biofabrication. 2017:9:2.

79. Daamen WF, Veerkamps JH, van Hest JCM, van Kuppevelt TH. Elastin as a biomaterial for tissue engineering. Biomaterials. 2007:28:4378-98.

80. Vaz CM, van Tuijl S, Bouten CVC, Baaijens FPT. Design of scaffolds for blood vessel tissue engineering using a multi-layering electrospinning technique. Acta Biomater. 2005;1:575-82. 
81. Lamme EN, de Vries HJ, van Veen H, Gabbiani G, Westerhof W, Middelkoop E. Extracellular matrix characterization during healing of full-thickness wounds treated with a collagen/elastin dermal substitute shows improved skin regeneration in pigs. J Histochem Cytochem. 1996;44:1311-22.

82. Hearst SM, Walker LR, Shao Q, Lopez M, Raucher D. The design and delivery of a thermally responsive peptide to inhibit S100B-mediated neurodegeneration. Neuroscience. 2011;197:369-80.

83. Johnson T, Koria P. Expression and Purification of Neurotrophin-Elastin-Like Peptide Fusion Proteins for Neural Regeneration. BioDrugs. 2016;30:117-27.

84. McGowan JWD, Shao Q, Vig PJS, Bidwell GL III. Intranasal administration of elastin-like polypeptide for therapeutic delivery to the central nervous system. Drug Des Devel Ther. 2016;10:2803-13.

85. Collins MN, Birkinshaw C. Hyaluronic acid based scaffolds for tissue engineering-A review. Carbohydr Polym. 2013;92:1262-79.

86. Suri S, Schmit CE. Cell-Laden Hydrogel Constructs of Hyaluronic Acid, Collagen, and Laminin for Neural Tissue Engineering. Tissue Eng Part A. 2010;16A:1703-16.

87. Thomas RC, Vu P, Modi SP, Chung PE, Landis RC, Khaing ZZ, Hardy JG, Schmidt CE. Sacrificial Crystal Templated Hyaluronic Acid Hydrogels As Biomimetic 3D Tissue Scaffolds for Nerve Tissue Regeneration. ACS Biomater Sci Eng. 2017;3:1451-9.

88. Pan L, Ren Y, Cui F, Xu Q. Viability and differentiation of neural precursors on hyaluronic acid hydrogel scaffold. J Neurosci Res. 2009;87:3207-20.

89. Liang $Y$, Walczak $P$, Bulte JWM. The survival of engrafted neural stem cells within hyaluronic acid hydrogels. Biomaterials. 2013;34:5521-9.

90. Seidlits SK, Khaing ZZ, Petersen RR, Nickels JD, Vanscoy JE, Shear JB, Schmidt CE. The effects of hyaluronic acid hydrogels with tunable mechanical properties on neural progenitor cell differentiation. Biomaterials. 2010;31:3930-40.

91. Zhang H, Wei YT, Tsang KS, Sun CR, Li J, Huang H, Cui FZ, An YH. Implantation of neural stem cells embedded in hyaluronic acid and collagen composite conduit promotes regeneration in a rabbit facial nerve injury model. J Transl Med. 2008;6:67.

92. Xu H, Zhang L, Bao Y, Yan X, Yin Y, Wang X, Huang Z, Peihu X. Preparation and characterization of injectable chitosan-hyaluronic acid hydrogels for nerve growth factor sustained release. J Bioact Compat Pol. 2016;32:146-62.

93. Wang Y, Wei YT, Zu ZH, Ju RK, Guo MY, Wang XM, Xu QY, Cui FZ. Combination of Hyaluronic Acid Hydrogel Scaffold and PLGA Microspheres for Supporting Survival of Neural Stem Cells. Pharm Res. 2011;28:6.

94. Wei $Y T$, He $Y, X u C L$, Wang $Y$, Wang $Y$, Liu BF, Wang XM, Sun XD, Cui FZ, Xu QY. Hyaluronic acid hydrogel modified with nogo-66 receptor antibody and poly-L-lysine to promote axon regrowth after spinal cord injury. J Biomed Mater Res part B Appl Biomater. 2010;95B:110-7.

95. Wang S, Guan S, Zhu Z, Li W, Liu T, Ma X. Hyaluronic acid doped-poly(3,4ethylenedioxythiophene)/chitosan/gelatin (PEDOT-HA/Cs/Gel) porous conductive scaffold for nerve regeneration. Mater Sci Eng C. 2017;71:308-16.

96. Lee JY, Schmidt CE. Pyrrole-hyaluronic acid conjugates for decreasing cell binding to metals and conducting polymers. Acta Biomater. 2010;6:4396-404

97. Lee KY, Mooney DJ. Alginate: properties and biomedical applications. Prog Polym Sci. 2012;37:106-26.

98. Suzukia Y, Taniharab M, Ohnishic K, Suzukia K, Endod K, Nishimuraa Y. Cat peripheral nerve regeneration across $50 \mathrm{~mm}$ gap repaired with a novel nerve guide composed of freeze-dried alginate gel. Neurosci Lett. 1999;259:75-8.

99. Hashimoto T, Suzuki Y, Kitada M, Kataoka K, Wu S, Suzuki K, Endo K, Nishimura $Y$, Ide $C$. Peripheral nerve regeneration through alginate gel: analysis of early outgrowth and late increase in diameter of regenerating axons. Exp Brain Research. 2002;146:356-68.

100. Wu S, Suzuki Y, Tanihara M, Ohnishi K, Endo K, Nishimura Y. Repair of facial nerve with alginate sponge without suturing: an experimetal study in cats. Scand J Plast Reconstr Surg Hand Surg. 2002;36:135-40.

101. Matsuura S, Obara T, Tsuchiya N, Suzuki Y, Habuchi T. Cavernous nerve regeneration by biodegradable alginate gel sponge sheet placement without sutures. Urology. 2006;68:1366-71

102. Kataoka K, Suzuki Y, Kitada M, Hashimoto T, Chou H, Bai H, Ohta M, Wu S, Suzuki K, Ide C. Alginate Enhances Elongation of Early Regenerating Axons in Spinal Cord of Young Rats. Tissue Eng. 2004;10:493-504.

103. Wu S, Suzuki Y, Tanihara M, Ohnishi K, Suzuki K, Endo K, Nishimura Y. Sciatic Nerve Regeneration Through Alginate With Tubulation or Nontubulation Repair in Cat. J Neurotrauma. 2004;18:329-38.

104. Hashimoto T, Suzuki Y, Suzuki K, Nakashima T, Tanihara M, Ide C. Review Peripheral nerve regeneration using non-tubular alginate gel crosslinked with covalent bonds. J Mater Sci: Mater Med. 2005;16:503-9.
105. Ansari S, Diniz IM, Chen C, Sarrion P, Tamayol A, Wu BM, Moshaverina A. Human Periodontal Ligament- and Gingiva-derived Mesenchymal Stem Cells Promote Nerve Regeneration When Encapsulated in Alginate/ Hyaluronic Acid 3D Scaffold. Adv Healthc Mater. 2017;6:24.

106. Golafshan N, Kharaziha M, Fathi M. Tough and conductive hybrid graphenePVA: Alginate fibrous scaffolds for engineering neural construct. Carbon. 2017;111:752-63.

107. Wang G, Wang X, Huang L. Feasibility of chitosan-alginate (Chi-Alg) hydrogel used as scaffold for neural tissue engineering: a pilot study in vitro. J Biotechnol Biotechnol Equip. 2017;31:4.

108. Sitoci-Ficici KH, Matyash M, Uckermann O, Galli R, Leipnitz E, Later R, Ikonomidou C, Gelinski M, Schackert G, Kirsch M. Non-functionalized soft alginate hydrogel promotes locomotor recovery after spinal cord injury in a rat hemimyelonectomy model. Acta Neurochir. 2018;160:449-57.

109. Liu S, Sadner B, Schackel T, Nicholson L, Chtarto A, Tenenbaum L, Puttagunta R, Müller R, Weidner N, Blesch A. Regulated viral BDNF delivery in combination with Schwann cells promotes axonal regeneration through capillary alginate hydrogels after spinal cord injury. Acta Biomater. 2017;60:167-80.

110. Prang P, Müller R, Eljaouhari A, Heckmann K, Kunz W, Weber T, Faber C, Vroemen $\mathrm{M}$, Bogdhan $\mathrm{U}$, Weidner $\mathrm{N}$. The promotion of oriented axonal regrowth in the injured spinal cord by alginate-based anisotropic capillary hydrogels. Biomaterials. 2006;27:3560-9.

111. Ansorena $E$, De Berdt $P$, Ucakar B, Simón-Yarza T, Jacobs D, Schakman O, Jankovski A, Deumens R, Blanco-Preito MJ, Préat $V$, des Rieux A. Injectable alginate hydrogel loaded with GDNF promotes functional recovery in a hemisection model of spinal cord injury. Int J Pharm. 2013:455:148-58.

112. Dash M, Chiellini F, Ottenbrite RM, Chiellini E. Chitosan-A versatile semisynthetic polymer in biomedical applications. Prog Polym Sci. 2011;36:981-1014.

113. Crompton KE, Goud JD, Bellamkonda RV, Gengenbach TR, Finkelstein DI, Horne MK, Forsythe JS. Polylysine-functionalised thermoresponsive chitosan hydrogel for neural tissue engineering. Biomaterials. 2007;28:441-9.

114. Valmikinathan CM, Mukhatyar VJ, Jain A, Karumbaiah L, Dasari M, Bellamkonda RV. Photocrosslinkable chitosan based hydrogels for neural tissue engineering. Soft Matter. 2012;8:1964-76.

115. Yi X, Jin G, Tian M, Mao W, Quin J. Porous chitosan scaffold and ngf promote neuronal differentiation of neural stem cells in vitro. Neuro Endocrinol Lett. 2011;32:705-10.

116. Wang A, Ao Q, Cao W, Yu M, He Q, Kong L, Zhang L, Gong Y, Zhang X. Porous chitosan tubular scaffolds with knitted outer wall and controllable inner structure for nerve tissue engineering. J Biomed Mater Res A. 2006;79A:36-46.

117. Li G, Xiao Q, McNaughton R, Han L, Zhang L, Wang Y, Yang Y. Nanoengineered porous chitosan/CaTiO3 hybrid scaffolds for accelerating Schwann cells growth in peripheral nerve regeneration. Colloids Surf B Biointerfaces. 2017;158:57-67.

118. Li G, Xiao Q, Zhang L, Zhao Y, Yang Y. Nerve growth factor loaded heparin/ chitosan scaffolds for accelerating peripheral nerve regeneration. Carbohydr Polym. 2017;171:39-49.

119. Shokrgozar MA, Mottaghitalab F, Mottaghitalab V, Farokhi M. Fabrication of Porous Chitosan/Poly(vinyl alcohol) Reinforced Single-Walled Carbon Nanotube Nanocomposites for Neural Tissue Engineering. J Biomed Nanotechnol. 2011;7:276-84.

120. Cooper A, Bhattarai N, Zhang M. Fabrication and cellular compatibility of aligned chitosan-PCL fibers for nerve tissue regeneration. Carbohydr Polym. 2011;85:149-56.

121. Kuo YC, Yeh CF, Yang JT. Differentiation of bone marrow stromal cells in poly(lactide-co-glycolide)/chitosan scaffolds. Biomaterials. 2009;30:6604-13.

122. Xue C, Hu N, Gu Y, Yang Y, Liu Y, Liu J, Ding F, Gu X. Joint Use of a Chitosan/PLGA Scaffold and MSCs to Bridge an Extra Large Gap in Dog Sciatic Nerve. Neurorehabil Neural Repair. 2012;26:96-106.

123. Huang YC, Huang CC, Huang YY, Chen KS. Surface modification and characterization of chitosan or PLGA membrane with laminin by chemical and oxygen plasma treatment for neural regeneration. J Biomed Mater Res A. 2007;82A:842-51.

124. Yu LMY, Kazazian K, Schoichet MS. Peptide surface modification of methacrylamide chitosan for neural tissue engineering applications. J Biomed Mater Res A. 2007:82A:243-55.

125. Hsu SH, Kuo WC, Chen YT, Yen CT, Chen YF, Chen KS, Huang WC, Cheng H. New nerve regeneration strategy combining laminin-coated chitosan conduits and stem cell therapy. Acta Biomater. 2013;9:6606-15. 
126. Skop NB, Calderon F, Levison SW, Gandhi CD, Cho CH. Heparin crosslinked chitosan microspheres for the delivery of neural stem cells and growth factors for central nervous system repair. Acta Biomater. 2013;9:6834-43.

127. Raj R, Wairkar S, Sridhar V, Gaud R. Pramipexole dihydrochloride loaded chitosan nanoparticles for nose to brain delivery: Development, characterization and in vivo anti-Parkinson activity. Int J Biol Macromol. 2018;109:27-35.

128. Liu SH, Ho PC. Intranasal administration of brain-targeted HP- $\beta-C D / c h i t o s a n$ nanoparticles for delivery of scutellarin, a compound with protective effect in cerebral ischaemia. J Pharm Pharmacol. 2017;69:1495-501.

129. Gu Q, Tomaskovic-Crook E, Lazano R, Chen Y, Kapsa RM, Zhou Q, et al. Functional 3D neural mini-tissues from printed gel-based bioink and human neural stem cells. Adv Healthc Mater. 2016;5:1429-38.

130. Shavandi A, Silva TH, Bekhit A, Bekhit AED. Keratin: dissolution, extraction and biomedical application. Biomater Sci. 2017;5:1699-735.

131. Labrador RO, Butí M, Navarro X. Influence of collagen and laminin gels concentration on nerve regeneration after resection and tube repair. Expl Neurol. 1998;149:243-52.

132. Apel PJ, Garrett JP, Sierpinski P, Ma J, Atala A, Smith TL, Koman LA, Van Dyke ME. Peripheral Nerve Regeneration Using a Keratin-Based Scaffold: Long-Term Functional and Histological Outcomes in a Mouse Model. J Hand Surg. 2008:33:1541-7.

133. Sierpinski P, Garrett J, Ma J, Apel P, Kloring D, Smith T, Koman LA, Atala A, Van Dyke $M$. The use of keratin biomaterials derived from human hair for the promotion of rapid regeneration of peripheral nerves. Biomaterials. 2008;29:118-28

134. Lin YC, Ramadan M, Van Dyke M, Kokai LE, Philips BJ, Rubin JP, Marra KG. Keratin Gel Filler for Peripheral Nerve Repair in a Rodent Sciatic Nerve Injury Model. Plast Reconstr Surg. 2012;129:67-78.

135. Hill PS, Apel PJ, Barnwell J, Smith T, Koman LA, Atala A, Van Dyke M. Repair of Peripheral Nerve Defects in Rabbits Using Keratin Hydrogel Scaffolds. Tissue Eng Part A. 2011;17:1499-505.

136. Pace LA, Plate JF, Mannava S, Barnwell JC, Koman LA, Zhongyu L, Smith TL, Van Dyke M. A Human Hair Keratin Hydrogel Scaffold Enhances Median Nerve Regeneration in Nonhuman Primates: An Electrophysiological and Histological Study. Tissue Eng Part A. 2013;20:507-17.

137. Mahanta B, Mary SA, Bhaduri A, Giridev VR, Electrospun PVA. Keratin Nanofibrous Scaffold and its Application in Neural Repair. Trends Biomater Artif Organs. 2014:28:188-96.

138. Kundu B, Kurland NE, Bano S, Patra C, Engel FB, Yadavalli VK, Kundu SC. Silk proteins for biomedical applications: Bioengineering perspectives. Prog Polym Sci. 2014;39:51-267

139. Hopkins AM, De Laporte L, Tortelli F, Spedden E, Staii C, Atherton TJ, Hubbell JA, Kaplan DL. Silk Hydrogels as Soft Substrates for Neural Tissue Engineering. Adv Funct Mater. 2013;23:5140-9.

140. Wang S, Ghezzi CE, White JD, Kaplan DL. Coculture of dorsal root ganglion neurons and differentiated human corneal stromal stem cells on silk-based scaffolds. J Biomed Mater Res part A. 2015;103A:3339-48.

141. Sun W, Incitti T, Migliaresi C, Quattrone A, Casarosa S, Motta A. Viability and neuronal differentiation of neural stem cells encapsulated in silk fibroin hydrogel functionalized with an IKVAV peptide. J Tissue Eng Regener Med. 2015;11:1532-41.

142. Midha S, Ghosh S. Silk-Based Bioinks for 3D Bioprinting. In: Mukhopadhyay A, editor. Regenerative Medicine: Laboratory to Clinic. Singapore: Springer Singapore; 2017. p. 259-76.

143. Benfenati V, Stahl K, Gomis-Perez C, Toffanin S, Sagnella A, Torp R, Kaplan DL, Ruani G, Omenetto FG, Zamboni R, Muccini M. Biofunctional Silk/ Neuron Interfaces. Adv Funct Mater. 2012;22:1871-84.

144. Zhang Q, Zhao Y, Yan S, Yang Y, Zhao H, Li M, Lu S, Kaplan DL. Preparation of uniaxial multichannel silk fibroin scaffolds for guiding primary neurons. Acta Biomater. 2012;8:2628-38.

145. Gennari CGM, Cilurzo F, Mitro N, Caruso D, Minghetti P, Magnaghi V. In vitro and in vivo evaluation of silk fibroin functionalized with GABA and allopregnanolone for Schwann cell and neuron survival. Regen Med. 2018;13:141-57.

146. Tian L, Prabhakaran MP, Hu J, Chen M, Besenbacher F, Ramakrishna S. Coaxial electrospun poly(lactic acid)/silk fibroin nanofibers incorporated with nerve growth factor support the differentiation of neuronal stem cells. RSC Adv. 2015;5:49838-48.

147. Dionigi C, Posati T, Benfenati V, Sagnella A, Pistone A, Bonetti S, Ruani G, Dinelli F, Padeletti G, Zamboni R, Muccini M. A nanostructured conductive bio-composite of silk fibroin-single walled carbon nanotubes. J Mater Chem B. 2014;2:1424-31.
148. Mottaghitalab F, Farokhi M, Zaminy A, Kokabi M, Soleimani M, Mirahmadi F, et al. A biosynthetic nerve guide conduit based on silk/SWNT/fibronectin nanocomposite for peripheral nerve regeneration. PLoS ONE. 2013;8:e74417.

149. Tsukada S, Nakashima H, Torimitsu K. Conductive Polymer Combined Silk Fiber Bundle for Bioelectrical Signal Recording. PLoS ONE. 2012;7:e33689.

150. Tien LW, Wu F, Tang-Schomer M, Yoon E, Omenetto FG, Kaplan DL. Silk as a Multifunctional Biomaterial Substrate for Reduced Glial Scarring around Brain-Penetrating Electrodes. Adv Funct Mater. 2013;23:3185-93.

151. Roloff F, Strauß S, Vogt PM, Bicker G, Radtke C. Spider Silk as Guiding Biomaterial for Human Model Neurons. Biomed Res Int. 2014;vol 2014(Article ID 906819):7.

152. Lewicka M, Hermanson O, Rising AU. Recombinant spider silk matrices for neural stem cell cultures. Biomaterials. 2012;33:7712-7.

153. Ricks CB, Shin SS, Becker C, Grandhi R. Extracellular matrices, artificial neural scaffolds and the promise of neural regeneration. Neural Regen Res. 2014;9:1573-7.

154. George PM, LaVan DA, Burdick JA, Chen CY, Liang E, Langer R. Electrically Controlled Drug Delivery from Biotin-Doped Conductive Polypyrrole. Adv Mater. 2006;18:577-81.

155. Cadotte AJ, DeMarse BT. Poly-HEMA as a drug delivery device for in vitro neural networks on micro-electrode arrays. J Neural Eng. 2005:2:114-22.

156. Nagesetti A, Srinivasan S, McGordon AJ. Polyethylene glycol modified ORMOSIL theranostic nanoparticles for triggered doxorubicin release and deep drug delivery into ovarian cancer spheroids. J Photochem Photobiol B: Biology. 2017;174:209-16.

157. Lou CW, Yao CH, Chen YS, Hsieh TC, Lin JH, Hsing WH. Manufacturing and Properties of PLA Absorbable Surgical Suture. Text Res J. 2008;78:958-65.

158. Chong EJ, Phan TT, Lim IJ, Zhang YZ, Bay BH, Ramakrishna S, Lim CT. Evaluation of electrospun PCL/gelatin nanofibrous scaffold for wound healing and layered dermal reconstitution. Acta Biomater. 2007;3:321-30.

159. Farzamfar S, Esmailpour F, Rahmati M, Vaez A, Mirzali M, Garmabi B, Shayannia A, Ebrahimi E, Vahedi H, Salehi M. Poly-lactic Acid/Gelatin Nanofiber (PLA/GTNF) Conduits Containing Platelet-Rich Plasma for Peripheral Nerve Regeneration. Int J Health Stud. 2017;3:29-32.

160. Carriel V, Alaminos M, Garzón I, Campos A, Cornelissen M. Tissue engineering of the peripheral nervous system. Expert Rev Neurother. 2014;14:301-18.

161. Moore AM, Kasukurthi R, Magill CK, et al. Limitations of conduits in peripheral nerve repairs. Hand. 2009:4:180-6.

162. Zeng CG, Xiong Y, Xie G, Dong P, Quan D. Fabrication and evaluation of PLLA multichannel conduits with nanofibrous microstructure for the differentiation of NSCs in vitro. Tissue Eng part A. 2014;20:1038-48.

163. Liu S, Sun X, Wang T, Chen S, Zeng CG, Xie G, Zhu Q, Liu X, Quan D. Nano-fibrous and ladder-like multi-channel nerve conduits: Degradation and modification by gelatin. Mater Sci Eng C. 2018;83:130-42.

164. Kim MS, Kim JW, Hyun JK. Development of Schwann cell-seeded multichannel scaffolds for peripheral nerve regeneration. J Neurol Sci. 2017:381:612-3

165. Mir M, Ahmed N, Rehman AU. Recent applications of PLGA based nanostructures in drug delivery. Colloids Surf B: Biointerfaces. 2017;159:217-31.

166. Garbayo E, Montero-Menei CN, Ansorena E, Lanciego JL, Aymerich MS, Blanco-Prieto MJ. Effective GDNF brain delivery using microspheres-A promising strategy for Parkinson's disease. J Control Release. 2009;135:119-26.

167. Ahmed E.M. Hydrogel:Preparation, characterization, and applications: A review. J Adv Res. 2015;6:105-21.

168. Zhu J. Bioactive Modification of Poly(ethylene glycol) Hydrogels for Tissue Engineering. Biomaterials. 2011;31:4639-56.

169. Lampe KJ, Mooney RG, Bjugstad KB, Mahoney MJ. Effect of macromer weight percent on neural cell growth in 2D and $3 \mathrm{D}$ nondegradable PEG hydrogel culture. J Biomed Mater Res part A. 2010;94A:1162-71.

170. Mahoney MJ, Anseth KS. Three-dimensional growth and function of neural tissue in degradable polyethylene glycol hydrogels. Biomaterials. 2006;27:2265-74.

171. Freudenberg U, Hermann A, Welzel PB, Stirl K, Schwartz SC, Grimmer M, Zieris A, Panyanuwat W, Zschoche S, Meinhold D, Storch A, Werner C. A star-PEG-heparin hydrogel platform to aid cell replacement therapies for neurodegenerative diseases. Biomaterials. 2009;30:5049-60.

172. Koob AO, Duerstock BS, Babbs CF, Sun YI, Borgens RB. Intravenous Polyethylene Glycol Inhibits the Loss of Cerebral Cells after Brain Injury. J Neurotrauma. 2005;22:1092-111.

173. Koob AO, Borgens RB. Polyethylene glycol treatment after traumatic brain injury reduces $\beta$-amyloid precursor protein accumulation in degenerating axons. J Neurosci Res. 2006;83:1558-63. 
174. Luo J, Borgens R, Shi R. Polyethylene glycol immediately repairs neuronal membranes and inhibits free radical production after acute spinal cord injury. J Neurochem. 2002:83:471-80.

175. Liu C, Huang Y, Pang M, Yang Y, Li S, Liu L, Shu T, Zhou W, Wang $X$, Rong L, Liu B. Tissue-Engineered Regeneration of Completely Transected Spinal Cord Using Induced Neural Stem Cells and Gelatin-Electrospun Poly (Lactide-Co-Glycolide)/Polyethylene Glycol Scaffolds. PLoS ONE. 2015;10:3.

176. Plant GW, Harvey AR, Chirila TV. Axonal growth within poly (2-hydroxyethyl methacrylate) sponges infiltrated with Schwann cells and implanted into the lesioned rat optic tract. Brain Res. 1995;61:119-30.

177. Dalton PD, Flynn L, Shoichet MS. Manufacture of poly(2-hydroxyethyl methacrylate-co-methyl methacrylate) hydrogel tubes for use as nerve guidance channels. Biomaterials. 2002;23:3843-51.

178. Flynn L, Dalton PD, Schoichet MS. Fiber templating of poly(2-hydroxyethyl methacrylate) for neural tissue engineering. Biomaterials. 2003;24:4265-72.

179. Kapur TA, Schoichet MS. Chemically-bound nerve growth factor for neural tissue engineering applications. J Biomater Sci Polym Ed. 2003;14:383-94.

180. Zhang LG, Kaplan DL. Neural Engineering: From Advanced Biomaterials to 3D Fabrication Techniques. New York: $1^{\text {st }}$ ed: Springer International Publishing; 2016

181. Guarino V, Zuppolini S, Borriello A, Ambrosio L. Electro-Active Polymers (EAPs): A Promising Route to Design Bio-Organic/Bioinspired Platforms with on Demand Functionalities. Polymers. 2016;8:185.

182. Lee JY, Bashur CA, Goldestain AS, Schimdt CE. Polypyrrole-coated electrospun PLGA nanofibers for neural tissue applications. Biomaterials. 2009;30:4325-35.

183. Xu H, Holzwarth JM, Yan Y, Xu P, Zheng H, Yin Y, Li S, Ma PX. Conductive PPY/ PDLLA conduit for peripheral nerve regeneration. Biomaterials. 2014;35:225-35.

184. Zhang Z, Rouabhia M, Wang Z, Roberge C, Shi G, Roche P, Li J, Dao LH. Electrically Conductive Biodegradable Polymer Composite for Nerve Regeneration: Electricity-Stimulated Neurite Outgrowth and Axon Regeneration. Artif Organs. 2007;31:13-22.

185. Shin J, Choi EJ, Cho JH, Cho AN, Jin K, Song C, Cho SW. ThreeDimensional Electroconductive Hyaluronic Acid Hydrogels Incorporated with Carbon Nanotubes and Polypyrrole by Catechol-Mediated Dispersion Enhance Neurogenesis of Human Neural Stem Cells. Biomacromolecules. 2017:18:3060-72.

186. Song S, George PM. Conductive polymer scaffolds to improve neural recovery. Neural Regen Res. 2017;12:1976-8.

187. Lu Y, Li T, Zhao X, Li M, Cao Y, Yang H, Duan YY. Electrodeposited polypyrrole/carbon nanotubes composite films electrodes for neural interfaces. Biomaterials. 2010;31:5169-81.

188. Evans AJ, Thmpson BC, Wallace GG, Millard R, O'Leary SJ, Clark GM, Sheperd RK, Richardson RT. Promoting neurite outgrowth from spiral ganglion neuron explants using polypyrrole/BDNF-coated electrodes. J Biomed Mater Res part A. 2009;91A:241-50

189. Kondyurin A, Tsoutas K, Latour QX, Higgins MJ, Moulton SE, McKenzie DR, Bilek MM. Structural Analysis and Protein Functionalization of Electroconductive Polypyrrole Films Modified by Plasma Immersion Ion Implantation. ACS Biomater Sci Eng. 2017;3:2247-58.

190. Wadhwa R, Lagenaur CF, Cui XT. Electrochemically controlled release of dexamethasone from conducting polymer polypyrrole coated electrode. J Control Release. 2006;110:531-41.

191. Bauquier SH, McLean KJ, Jiang JL, Boston RC, Lai A, Yue Z, Moulton SE, Halliday AJ, Wallace G, Cook MJ. Evaluation of the Biocompatibility of Polypyrrole Implanted Subdurally in GAERS. Macromol Biosci. 2017;17:5.

192. Kumar V, Yokozeki T, Goto T, Takahashi T. Mechanical and electrical properties of PANI-based conductive thermosetting composites. J Reinf Plast Comp. 2015;34:1298-305

193. Bhang SH, Jeong SI, Lee TJ, Jun TJ, Jun I, Lee YB, Kim BS, Shin H. Electroactive Electrospun Polyaniline/Poly[(L-lactide)-co-( $\varepsilon$-caprolactone)] Fibers for Control of Neural Cell Function. Macromol Biosci. 2011;12:402-11.

194. Fan L, Xiong Y, Fu Z, Xu D, Wang L, Chen Y, Xia H, Oeng N, Ye S, Wang Y, Zhang $L$, Ye Q. Polyaniline promotes peripheral nerve regeneration by enhancement of the brain-derived neurotrophic factor and ciliary neurotrophic factor expression and activation of the ERK1/2/MAPK signaling pathway. Mol Med Rep. 2017;16:7534-40.

195. Xu B, Bai T, Sinclair A, Wang W, Wu Q, Gao F, Jia H, Jiang S, Liu W. Directed neural stem cell differentiation on polyaniline-coated high strength hydrogels. Mater Today Chem. 2016;1:15-22.
196. Cui C, Faraji N, Lauto A, Travaglini L, Tonkin J, Mahns J, Humprey E, Terracino C, Gooding JJ, Seidel J, Mawad D. A flexible polyaniline-based bioelectronic patch. Biomater Sci. 2018;6:493-500.

197. Ludwig KA, Langhals NB, Joseph MD, Richardson-Burns SM, Hendricks JL, Kipke DR. Poly(3,4-ethylenedioxythiophene) (PEDOT) polymer coatings facilitate smaller neural recording electrodes. J Neural Eng. 2011;8:1.

198. Venkatraman S, Hendricks J, King ZA, Sereno AJ, Richardson-Burns S, Martin D, Carmena JM. In Vitro and In Vivo Evaluation of PEDOT Microelectrodes for Neural Stimulation and Recording. IEEE Trans Neural Syst Rehab Eng. 2011;19:307-16.

199. Luo X, Weaver CL, Zhou DD, Greenberg R, Cui XT. Highly stable carbon nanotube doped poly(3,4-ethylenedioxythiophene) for chronic neural stimulation. Biomaterials. 2011;32:5551-7.

200. Alba NA, Du ZJ, Catt KA, Kozai TD, Cui XT. In Vivo Electrochemical Analysis of a PEDOT/MWCNT Neural Electrode Coating. Biosensors. 2015;5:618-46.

201. Kolarcick CL, Catt K, Rost E, Albrecht IN, Bourbeau D, Du Z, Kozai X, Weber DJ, Cui XT. Evaluation of poly(3,4-ethylenedioxythiophene)/carbon nanotube neural electrode coatings for stimulation in the dorsal root ganglion. J Neural Eng. 2015;12:1.

202. Pires F, Ferreira Q, Rodrigues CA, Morgado CAV, Castelo Ferreira F. Neural stem cell differentiation by electrical stimulation using a cross-linked PEDOT substrate: Expanding the use of biocompatible conjugated conductive polymers for neural tissue engineering. Biochim Biophys Acta Gen Subj. 2015;1850:1158-68.

203. Ostrakhovitich EA, Byers JC, O'Neil KD, Semenikhin OA. Directed differentiation of embryonic P19 cells and neural stem cells into neural lineage on conducting PEDOT-PEG and ITO glass substrates. Arch Biochem Biophys. 2012;528:21-31.

204. Gautam V, Naureen S, Shahid N, Gao Q, Wang Y, Nisbet D, Jagadish C, Daria VR. Engineering Highly Interconnected Neuronal Networks on Nanowire Scaffolds. Nano Lett. 2017;17:3369-75.

205. Zhang Y, Ali SA, Dervishi E, Xu Y, Li Z, Casciano D, Birist AS. Cytotoxicity Effects of Graphene and Single-Wall Carbon Nanotubes in Neural Phaeochromocytoma-Derived PC12 Cells. ACS Nano. 2010;4:3181-6.

206. Song Q, Jiang Z, Li N, Liu P, Liu L, Tang M, Cheng G. Anti-inflammatory effects of three-dimensional graphene foams cultured with microglial cells. Biomaterials. 2014;35:6930-40.

207. Li N, Zhang Q, Gao S, Song Q, Huang R, Wang L, Liu L, Dai J, Tang M, Cheng $\mathrm{G}$. Three-dimensional graphene foam as a biocompatible and conductive scaffold for neural stem cells. Sci Rep. 2012;3:1604.

208. Akhavan O, Ghaderi E. Differentiation of human neural stem cells into neural networks on graphene nanogrids. J Mater Chem B. 2013;1:6291-301.

209. Akhavan O, Ghaderi E. Flash photo stimulation of human neural stem cells on graphene/TiO2 heterojunction for differentiation into neurons. Nanoscale. 2013;5:10316-26.

210. Akhavan O, Ghaderi E. The use of graphene in the self-organized differentiation of human neural stem cells into neurons under pulsed laser stimulation. J Mater Chem B. 2014:2:5602-11.

211. Akhavan O, Ghaderi E, Shirazian SA. Near infrared laser stimulation of human neural stem cells into neurons on graphene nanomesh semiconductors. Colloids Surf B: Biointerfaces. 2015;126:313-21.

212. Park DW, Schendel AA, Mikael S, Brodnick SK, Richner TJ, Ness JP, Hayat MR, Atry F, Frye ST, Pashaie R, Thongpang S, Ma Z, Williams JC. Graphene-based carbon-layered electrode array technology for neural imaging and optogenetic applications. Nat Commun. 2014;5:5258.

213. Lee W, Parpura V. Carbon nanotubes as substrates/scaffolds for neural cell growth. In: Sharma HS, editor. Progress in Brain Research; 2009. p. 110-25.

214. Gheith MK, Pappas TC, Liopo AV, Sinani VA, Shim BS, Motamedi M, Wicksted JP, Kotov NA. Stimulation of Neural Cells by Lateral Currents in Conductive Layer-byLayer Films of Single-Walled Carbon Nanotubes. Adv Mater. 2006;18:2975-9.

215. Malarkey EB, Fisher KA, Bekyarova E, Liu W, Haddon RC, Parpura V. Conductive Single-Walled Carbon Nanotube Substrates Modulate Neuronal Growth. Nano Lett. 2009:9:264-8.

216. Ni Y, Hu H, Malarkey EB, Zhao B, Montana V, Haddon RC, Parpura V. Chemically Functionalized Water Soluble Single-Walled Carbon Nanotubes Modulate Neurite Outgrowth. J Nanosci Nanotechnol. 2005;5:1707-12.

217. Jan E, Kotov NA. Successful Differentiation of Mouse Neural Stem Cells on Layer-by-Layer Assembled Single-Walled Carbon Nanotube Composite. Nano Lett. 2007;7:1123-8.

218. Lee SJ, Zhu W, Nowicki M, Lee G, Heo DN, Kim J, Zuo YY, Zhang LG. 3D printing nano conductive multi-walled carbon nanotube scaffolds for nerve regeneration. J Neural Eng. 2018;15:1. 
219. Bardi G, Nunes A, Gherardini L, Bates K, Al-Jamal KT, Gaillard C, Prato M, Bianco A, Pizzorusso T, Kostarelos K. Functionalized Carbon Nanotubes in the Brain: Cellular Internalization and Neuroinflammatory Responses. PLoS ONE. 2013;8:11.

220. Wu S, Duan B, Lu A, Wang Y, Ye Q, Zhang L. Biocompatible chitin/carbon nanotubes composite hydrogels as neuronal growth substrates. Carbohydr Polym. 2017;174:830-40.

221. Tian P, Yi W, Chen C, Hu J, Qi J, Zhang B, Cheng MC. Flexible 3D carbon nanotubes cuff electrodes as a peripheral nerve interface. Biomed Microdevices. 2018;20:21

Ready to submit your research? Choose BMC and benefit from:

- fast, convenient online submission

- thorough peer review by experienced researchers in your field

- rapid publication on acceptance

- support for research data, including large and complex data types

- gold Open Access which fosters wider collaboration and increased citations

- maximum visibility for your research: over $100 \mathrm{M}$ website views per year

At BMC, research is always in progress.

Learn more biomedcentral.com/submissions 